Chapter 4

\title{
Severe Cutaneous Adverse Reactions
}

\author{
Suran L. Fernando \\ Additional information is available at the end of the chapter \\ http://dx.doi.org/10.5772/54820
}

\section{Introduction}

Severe cutaneous adverse reactions (SCARs) are generally induced by drugs and encompass the conditions of Stevens-Johnson syndrome (SJS) and toxic epidermal necrolysis (TEN), drug induced eosinophilia and systemic syndrome (DRESS) also known as drug induced hypersensitivity syndrome (DIHS), and acute generalized exanthematous pustulosis (AGEP). These conditions, although rare, cause significant morbidity and are potentially fatal. It is therefore important for the treating physician to promptly recognize SCARs through the identification of their characteristic clinical features so that the offending drug is promptly withdrawn and supportive and adjunctive therapies are administered. SCARs are accompanied by particular abnormalities on routine laboratory investigations and skin biopsy that enables confirmation of the diagnosis and provision of useful prognostic information. Data bases have been established, predominantly in Europe, since the 1980s to characterize the epidemiology of SCARs including the identification of drugs with the highest relative risk and the latency between the commencement of drug intake and the onset of clinical manifestations. The pathogenesis of the various SCARs involves delayed T cellmediated inflammation in a genetically predisposed individual and in the case of DIHS, may involve viral factors. The emerging field of the genetic susceptibility to SCARs has raised the important issue of pharmacogenetic screening as a method of predicting an individual's risk of developing SCAR to a certain drug. The treatment of SJS/TEN is dependent on supportive care in a suitable settling such as a Burns Unit and the role of immunomodulatory agents is not well defined and is not robustly supported in the literature by prospective studies. The evidence for the use of immunomodulatory agents and ganciclovir is emerging in the treatment of DIHS/DRESS. AGEP usually has favourable prognosis if the offending drug is withdrawn but a course of corticosteroids may hasten recovery. 


\subsection{SJS/TEN}

Stevens-Johnson Syndrome (SJS), first described in 1922 as an acute mucocutaneous syndrome in two boys, and Toxic Epidermal Necrolysis (TEN), first described as a scalding eruption of the skin in 1956 in four patients, are now considered to lie along the spectrum of epidermal necrolysis. The terminology is based on the extent of epidermal detachment; SJS indicates that there is less than $10 \%$ detachment of the body surface area, TEN greater than $30 \%$, and SJS/TEN overlap between 10 and $30 \%$.

The clinical presentation is characterized by a rash featuring target-like lesions, and mucositis involving the ocular, oropharyngeal and genital surfaces. The patient is also systemically unwell with fever and malaise. The EuroSCAR case control study collected 379 cases of SJS/TEN between 1997 and 2001 from 6 countries encompassing over 100 million inhabitants. The estimated incidence is 1-2 per million per year. The drugs associated with the highest relative risk include allopurinol, antibacterial sulphonamides, oxicam non-steroidal antiinflammatory drugs (NSAIDs), aromatic anticonvulsants (phenytoin, carbamazepine, phenobarbital), lamotrigine, and nevirapine. The latency between the intake of these high-risk drugs and the onset of clinical manifestations is 1 to 8 weeks. Other factors influencing risk include the presence of other diseases (HIV, malignancy, autoimmune disease, recent radiotherapy, acute infection within the last four weeks) and pharmacokinetic factors (dose of allopurinol commenced at 200-300 mg daily). Recently, genes conferring strong susceptibility to SJS/TEN have been identified, the most prominent of which are HLA-B*1502 and carbamazepine in individuals of Asian ancestry, HLA-A*3101 and carbamazepine in individuals from Northern European ancestry, and HLA-B 5801 and allopurinol in various racial groups. A black box warning has been placed by the Food and Drugs Administration and Health Canada alerting physicians to not only to be aware of the risk of carbamazepine and SJS/TEN in Asians but to also screen at risk individuals for the susceptibility allele. Currently, this strategy has been limited by the lack of availability of cost-effective pharmacogenetic testing methods to the general physician.

The immunopathogenesis of SJS/TEN involves the release of granulysin by CD8 cytotoxic T cells and natural killer cells within the epidermis resulting in apoptosis of keratinocytes. Apoptosis may also result from the degranulation of perforin and granzyme by CD8 cytotoxic $\mathrm{T}$ cells and the ligation of Fas on keratinocytes by Fas-ligand (Fas-L). The source of Fas-L is still unclear with CD8 cells and keratinocytes proposed as candidates. Histologically, the resultant widespread apoptosis of keratinocytes results in necrosis of the epidermis and dermoepidermal separation at the level of the stratum spinosum. Direct immunofluorescence of skin biopsies in SJS/TEN is negative differentiating it from autoimmune vesiculobullous diseases.

The diagnosis is made clinically and confirmed histologically. Skin testing is contraindicated given the risk of precipitating a generalized reaction. In vitro tests are currently not widely available and relatively poor sensitivity. Lymphocyte transformation tests that assess the proliferative response of T cells to the drug have a sensitivity of $60-70 \%$ and are more likely to be positive if performed within 6 weeks of the onset of the disease. Cytotoxicity assays that 
determine the extent of degranulation of cytotoxic T cells by flow cytometry or ELISA may prove useful in the future.

The treatment of SJS involves the removal of the offending drug and supportive treatment depending on severity and availability in a burns unit to address the manifestations and complications of acute skin failure including monitoring of fluid-electrolyte balance, provision of enteral or parenteral nutrition, wound care and treatment of sepsis. In addition, supportive care of affected mucosal surfaces is required. This includes aggressive ocular lubrication, topical corticosteroids and topical antibiotics, hygienic mouthwashes and topical oral anaesthetics, and monitoring for urinary retention. Large randomized trials on the benefits of immunomodulatory therapy is lacking but there is sufficient evidence to recommend the administration of intravenous immunoglobulin (IVIg) as it contains anti-FasL antibodies and as a result may halt further epidermal necrosis and hasten re-epithelialization. Cyclosporin due to its effects on cytotoxic T cell depletion has reported to be of benefit in a number of small studies. A number of early studies revealed that systemic corticosteroids may be not be beneficial in the treatment of SJS/TEN and in fact may be harmful by promoting sepsis but these conclusions may have been partly explained by the inadequate doses administered and the delay in initiating treatment. Recent studies have demonstrated benefit in the immediate use of high dose pulse methylprednisolone, especially in reducing the rate of ocular complications. The application of amniotic membranes to the conjunctival surface may also prove beneficial in minimising ocular sequelae such as dry eye, cicatrization and in rare cases, corneal perforation.

The mortality rate of SJS/TEN is high; approximately $10 \%$ for SJS and $50 \%$ for TEN. A score for the evaluation of TEN (SCORTEN) has proven remarkably accurate in predicting mortality through identification of 6 risk factors; age $>40$ years, presence of malignancy, heart rate $>120$ / min, epidermal detachment $>10 \%$, serum urea $>10 \mathrm{mmol} / \mathrm{L}(28 \mathrm{mg} / \mathrm{dL})$, serum glucose $>14$ $\mathrm{mmol} / \mathrm{L}(252 \mathrm{mg} / \mathrm{dL})$ and serum bicarbonate $<20 \mathrm{mmol} / \mathrm{L}(20 \mathrm{mEq} / \mathrm{L})$.

\section{DIHS/DRESS}

DIHS/DRESS is also referred to as hypersensitivity syndrome and when caused by antiepileptic drugs it has been often referred to as anticonvulsant hypersensitivity. The condition is characterised by fever, rash, lymphadenopathy, eosinophilia and/or other leukocyte abnormalities, and internal organ involvement such as hepatitis. Reactivation of human herpes virus (HHV)-6 is also considered by some groups to be an instrumental component of the condition. The rash typically begins as patchy erythematous macules that become confluent and progresses especially if the causative drug is not withdrawn to an erythroderma or exfoliative dermatitis. The syndrome typically develops between 3 weeks and 3 months after the starting therapy and a limited number of drugs appear involved in its causation. They include anticonvulsants (phenytoin, carbamazepine, phenobarbital, lamotrigine, zonisaminde), allopurinol, sulphonamides (dapsone, sulphasalazine), antiretrovirals (abacavir, nevirapine), minocycline, strontium ranelate, and mexilitene. The precise incidence according to the latest 
case definition will be determined by RegiSCAR study, which comprises data collected from 6 European countries and the JSCAR Japanese registry. The incidence following phenytoin therapy is estimated to be 1 in 1000 to 10000 exposures.

DIHS has a relapsing remitting course lasting several weeks to months despite the withdrawal of the offending drug and this has been postulated to result from the sequential reactivation of herpes viruses analogous to that observed in graft versus host disease. The precise role of HHV-6 in DIHS is unclear. One theory is that HHV-6 triggers DIHS through its reactivation within T cells resulting in HHV-6 stimulated T cells cross-reacting with the culprit drug, following which there is sequential activation of heterologous herpes viruses. The alternative explanation is that drug specific $\mathrm{T}$ cells are activated resulting in reactivation of the viral genome and sequential reactivation of herpes viruses.

The histological features of DIHS are relatively non-specific and typically comprise a superficial perivascular lymphocytic infiltrate. As the understanding of the disease mechanisms emerge, novel findings such as granulomatous inflammation have also been identified.

The diagnostic criteria consist of the typical clinical features and laboratory abnormalities. Confirmation of the role of the causative agent by skin testing is contraindicated because of the risk of a generalized reaction. The utility of LTTs is unclear as they are often negative early in the course of disease possibly as a result of regulatory T cell activation. LTTs may become positive after 5-7 weeks as the expanded regulatory $\mathrm{T}$ cell population are removed by apoptosis at the end of the immune response.

A prolonged course of oral corticosteroids is required to treat DIHS given the relapsing remitting nature of the condition. The mortality rate is estimated to be $10-20 \%$.

\section{AGEP}

AGEP is rare with an incidence of 1-5 cases per million per year. The clinical manifestations are characterised by fever and the rapid appearance of disseminated sterile pustules 3-5 days after the commencement of treatment. It is accompanied by a marked neutrophilia. Mucous membranes are not typically involved. The drugs conferring the highest risk of AGEP according to the EuroSCAR study are aminopenicillins, pristinamycin, hydroxychloroquine, antibacterial sulphonamides, terbinafine and diltiazem. The pathogenesis of AGEP involves the initial influx of CD8 cytotoxic T cells resulting in apoptosis of keratinocytes and formation of vesicles. Then CXCL-8 producing CD4 cells enter the epidermis resulting in neutrophil mediated inflammation and formation of pustules. As a result the histology reveals intraepidermal usually subcorneal pustules and an accompanying neutrophilic and lymphocytic infiltrate. Epicutaneous patch testing may also support the diagnosis by causing a localized pustular reaction 48-96 hours after the offending drug is applied. The condition usually resolves by 15 days after the causative drug is withdrawn but oral corticosteroid therapy may be necessary in some individuals. The mortality rate is up to $5 \%$ and mostly occurs in the elderly who have significant comorbidities. 


\section{Stevens-Johnson Syndrome/Toxic Epidermal Necrolysis}

\subsection{History and nosology}

SJS and TEN were once considered as variants of erythema multiforme (EM), a condition first described by Ferdinand von Hebra in 1860 [1] as a mild and relapsing eruption of target lesions affecting the acral regions. Mucosal involvement occurs in up to $70 \%$ of cases of EM. In 1922, two American paediatricians, Albert Stevens and Frank Johnson, described two cases of fever, stomatitis, purulent conjunctivitis, and a generalized eruption of purple papules in boys aged 7 and 8 years, respectively [2]. Both cases were distinguished from EM by the prolonged high fever, and the generalized distribution and heavy terminal crusting of the skin lesions. Bernard Thomas proposed two categories of EM in 1950: erythema multiforme minor, as described by von Hebra, and erythema multiforme major, a severe form that encompassed SJS [3]. Alan Lyell, a Scottish dermatologist, termed the condition toxic epidermal necrolysis (TEN) after reporting four cases of an acute life threatening mucocutaneous disorder characterized by diffuse erythema followed by extensive epidermal detachment manifesting as blistering and sloughing of the skin [4]. Although SJS and TEN were initially considered distinct entities, it was later proposed that they form a continuum along the same disease process and differ mainly in the extent of involvement [5],[6]. It was also proposed that EM major and SJS are distinct conditions, with EM major characterised by acral target-like lesion typical of EM minor but with mucosal involvement. SJS was applied to cases of mucous membrane involvement and a more extensive eruption of atypical targetoid lesions, blisters or sloughing of the skin [7]. The distinction between EM and SJS are consistent with observations regarding differences in etiology, demography and histopathology and not just confined to variations in the severity of disease. Most cases of EM are related to infection especially those with recurrent disease, which is related to herpes simplex virus (HSV) infection [8]-[10] in contrast to SJS which usually is an idiosyncratic reaction to drugs [11]. EM typically affects young adults in their 20s and 30s although approximately $20 \%$ of cases involve children [12],[13] whereas SJS/TEN occurs at any age [11]. Histopathology in EM in contrast to SJS/TEN consists of a denser infiltrate of lymphocytes and less apoptosis of keratinocytes [14].

In 1993, a classification scheme was proposed that is widely but not universally adopted that arbitrarily defines SJS and TEN according to the extent of epidermal detachment [7]. In SJS, epidermal loss affects less than $10 \%$ of the total body surface area (TBSA) whereas TEN involves greater than $30 \%$ of the TBSA. Epidermal detachment between 10 and $30 \%$ of the TBSA is classified as SJS/TEN overlap.

\subsection{Epidemiology}

The epidemiology of SJS/TEN and other severe cutaneous adverse reactions (SCARs) has been more accurately determined in recent years due to registries that have been established mainly across Europe comprising cases that are reviewed by expert committees and based on predefined and validated criteria. A population-based registry was commenced in Germany in 1990 to collect all hospitalised cases of SJS, TEN and EM major [15]. An international casecontrol study was conducted between 1989 and 1995 in France, Germany, Italy and Portugal 
(SCAR study) focusing on cases of SJS/TEN requiring hospitalisation [16],[17]. A European case-control surveillance study of SCARs (EuroSCAR study) was conducted between 1997 and 2001 in Austria, France, Germany, Israel, Italy, and the Netherlands investigating both SJS/TEN [11] and AGEP [18] that resulted in admission to hospital. In 2003, the European registry on SCARs (RegiSCAR) was commenced collecting biological samples across the same countries that participated in the EuroSCAR study. This network, which is focused on SJS/TEN and AGEP, has spawned numerous studies on epidemiology, pharmacogenetics and histopathology and includes community cases that requiring hospitalisation as well as cases that developed during hospital admissions. These registries not only provide valuable information on the epidemiology of SCAR but they have enabled close scrutiny of the availability and prescription of high-risk drugs. For example, the SCAR study resulted in the withdrawal of chlormezanone from the market and restricted indications for cotrimoxazole and phenobarbitol [17].

The incidence of SJS/TEN is 1-2 cases/million inhabitants/year [15]. The EuroSCAR study published in 2008 comprised 379 cases that included 134 cases of SJS, 136 cases of SJS/TEN overlap, and 109 cases TEN spanning a geographical area encompassing over a 100 million inhabitants. The median age of cases was found to be 50 years (range 1-95 years), and a female preponderance (62\% of cases) was noted [11].

\subsection{Etiology}

\subsubsection{Drugs}

Drugs are nearly always the cause of SJS/TEN. Over 220 medications have been implicated but only relatively a few are responsible for the majority of cases. The EuroSCAR study comprised 379 cases of SJS/TEN and 1505 age-matched controls, who were patients admitted to hospital for other acute illnesses [11]. Univariate relative risk (uRR) and multivariate relative risk (mRR) were calculated for each drug suspected of causing SJS/TEN. The drugs found to confer the highest risk were cotrimoxazole (uRR 102), other anti-bacterial sulphonamides (uRR 53), carbamazepine (mRR 72), nevirapine ( $\mathrm{uRR}>22)$, allopurinol (mRR 18), phenytoin (mRR 17), oxicam-NSAIDs (mRR 16), lamotrigine ( $\mathrm{uRR}>14$ ), and sertraline (mRR 11). Drugs that were found to have a significant but lower risk included acetic acid-NSAIDs, macrolides, quinolones, cephalosporins, tetracyclines and aminopenicillins. SJS/TEN typically occurs with drugs that are taken on a long-term basis. The median latency between the onset of medication use and the occurrence of SJS/TEN in the EuroSCAR study was found to be less than 4 weeks (range 1-8 weeks): carbamazepine 15 days, phenobarbitol 17 days, allopurinol 20 days, phenytoin 24 days. Pantoprazole and tramadol were associated with high uRRs, 18 and 20, respectively, but the frequent co-medication with highly suspected drugs and the timing of the onset of SJS/TEN were not suggestive of a true risk. Commonly used medications not associated with a risk of SJS/TEN included beta-blockers, ACE-inhibitors, calcium channel blockers, thiazide diuretics, furosemide, propionic acid-NSAIDs, sulphonylureas, and insulin. Interestingly, valproic acid was not shown to have a significant risk, which is in contrast to previous 
observations [17],[19]. The most likely explanation is that valproic acid was frequently coadministered with high-risk drugs.

A pooled analysis of the SCAR and EuroSCAR data was performed for children under 15 years of age and showed that anti-bacterial sulphonamides, phenobarbitol, lamotrigine and carbamazepine were strongly associated with SJS/TEN in this paediatric population [20].

\subsubsection{Other causes}

Infection with Mycoplasma pneumoniae is a known cause of SJS especially in the paediatric population and a few cases of TEN have been reported to complicate infection with this agent [13],[21]. However, the EuroSCAR study, failed to show that infection is a risk factor on its own although there is a suggestion that it may modestly increase the risk of SJS/TEN from medication. SJS/TEN has been reported in association with vaccinations [22] and exposure to industrial chemicals and fumigants [23].

\subsection{Clinical presentation}

SJS/TEN is characterized, as per the original descriptions, by fever, blistering skin eruption and severe mucositis [2],[4]. The skin lesions initially appear as atypical target-like or targetoid lesions, which are erythematous macules that contain a central purpuric blister (Fig. 1). Lesions

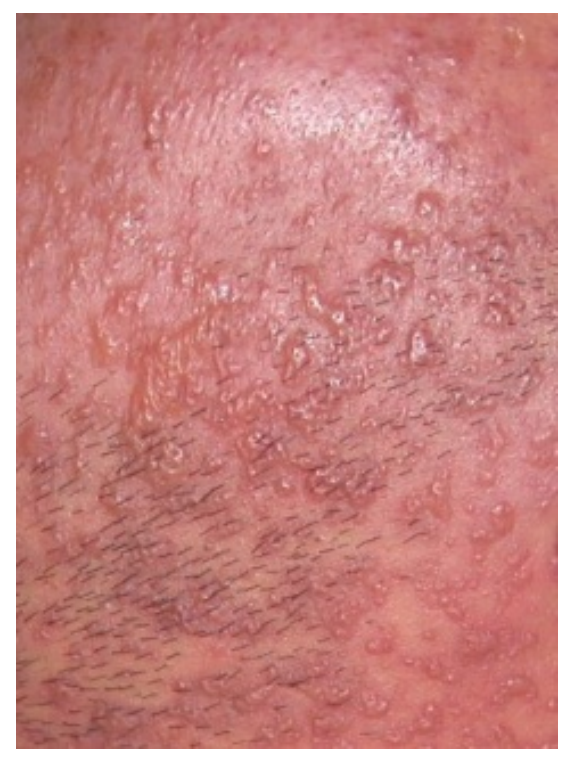

Figure 1. Atypical target-like or targetoid lesions in a patient with SJS characterized by an erythematous macule with a central blister. 
are symmetrically distributed often starting on the face and thorax before spreading to other areas (Fig. 2). The scalp is typically spared. Blisters result from epidermal detachment and they are easily breached resulting in dark red oozing erosions. Lesions exhibit Nikolsky's sign, which is epidermal separation induced by gentle lateral pressure applied to the skin surface. The skin then sloughs rapidly over several days as a result of separation of large sheets of the epidermis from the dermis. Fulminant cases of TEN have been reported were total loss of the epidermis occurs within 24 hours ${ }^{[24]}$. New lesions may continue to erupt for up to 4 weeks. However, the growth of a new epithelium occurs after several days and individual lesions are completely re-epithelialized after a mean of 3 weeks. Cicatrization of the mucous membranes may take longer to complete.

At least two mucosal surfaces are involved in 90\% of cases of SJS/TEN [25]. Oropharyngeal involvement causes severe pain and odynophagia as a result of erosion and crusting (Fig. 3). Ocular regions may show a purulent conjunctivitis, pseudomembrane formation and corneal ulceration as a result of sloughing of conjunctival and corneal epithelia (Fig. 4). Urethritis may result in dysuria and even urinary retention. Sloughing of the tracheal and bronchial epithelium occurs in up to $30 \%$ of cases and may result in hypoxia, bronchial hypersecretion, pulmonary edema and bronchiolitis obliterans and the need for mechanical ventilation [26], [27]. The gastrointestinal tract can also be involved resulting in per rectal bleeding [28].

The mortality of SJS is generally below $10 \%$ whereas $30-50 \%$ of TEN patients die in the acute phase of the illness mostly as a result of skin failure. Infection and sepsis with multiorgan failure is the most common of death. The causative organisms are usually Staphylococcus aureus and Pseudomonas aeruginosa [29]. Fluid and electrolyte imbalances occur as a result of increased transepidermal water loss and impaired intake of nutrition due to odynophagia from stomatitis. Less common fatal complications include adult respiratory distress syndrome, pulmonary embolism and gastrointestinal haemorrhage [30],[31]. Mortality is accurately predicted by the SCORTEN scale (Table 1) and should be computed within 24 hours and 3 days following admission [32]-[34].

Chronic complications occur frequently following the acute phase of SJS/TEN. The most serious sequelae relate to the eye. The chronic ocular consequences are that of a cicatrization of the conjunctiva and symblepharon formation, severe dry eye, trichiasis, eyelid margin keratinization, and limbal stem cell deficiency, all of which combine to cause corneal ulceration and scarring and loss of vision (Fig. 5) [35],[36]. Patients may also experience chronic photophobia and eye pain [37]. Skin sequelae include scarring, pigmentation abnormalities, and shedding of hair and nails [38]. Vulvovaginal involvement can result in stenosis [39]. Vulvar adenosis can occur in young women several years after resolution of the acute episode and can present with tender, erosive, haemorrhagic lesions [40]. Phimosis can occur in men [41]. Bronchopulmonary complications confer a poor prognosis and include chronic bronchitis, bronchiolitis obliterans, bronchiolitis obliterans with organizing pneumonia, bronchiectasis $[42],[43]$ Oesophageal stricture and webbing has also been described and can result in dysphagia [44]. 


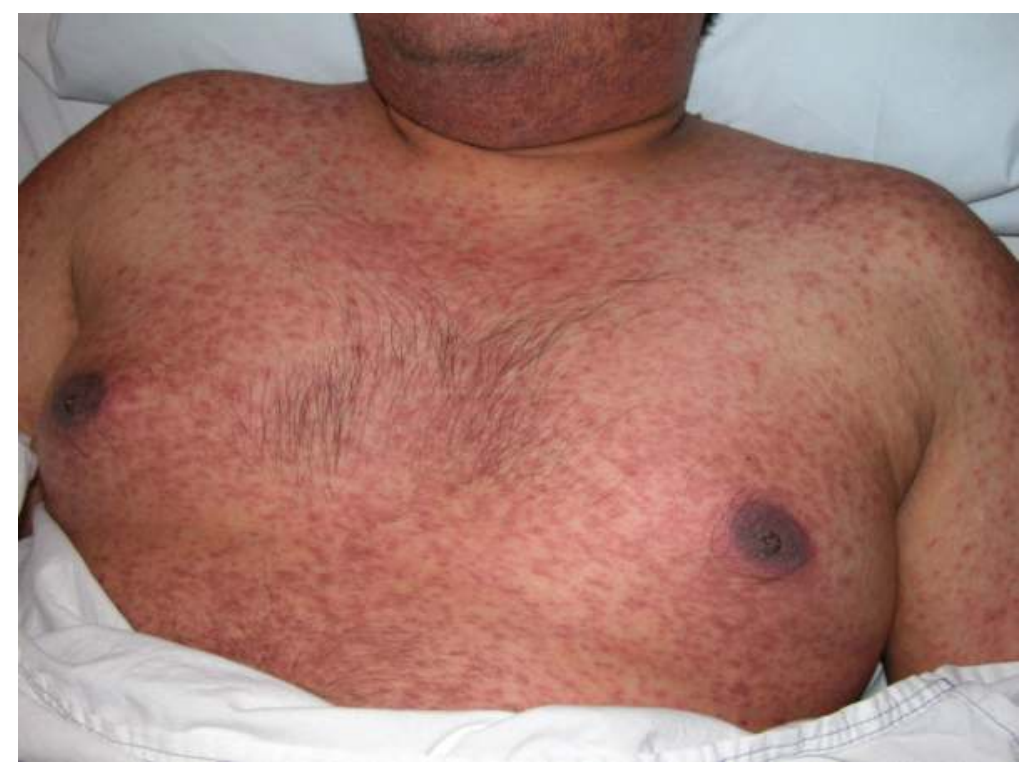

(a)

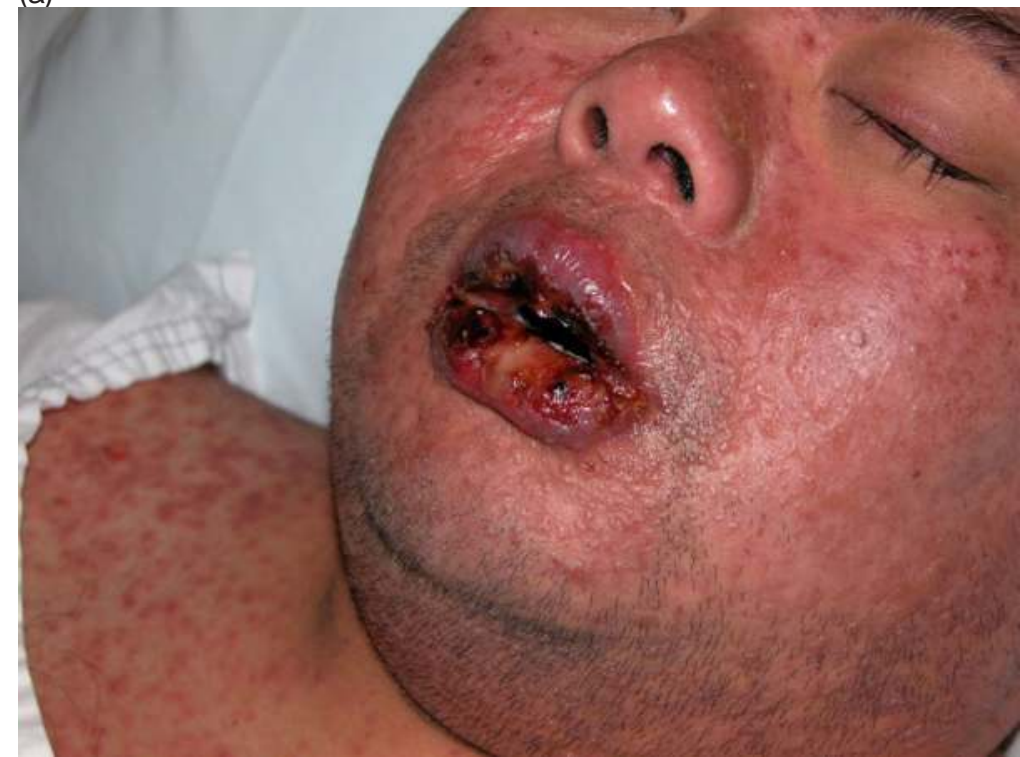

(b)

Figure 2. Symmetrical distribution of targetoid lesions in a patient with SJS, which typically first appear on the face and thorax before spreading to other areas. 


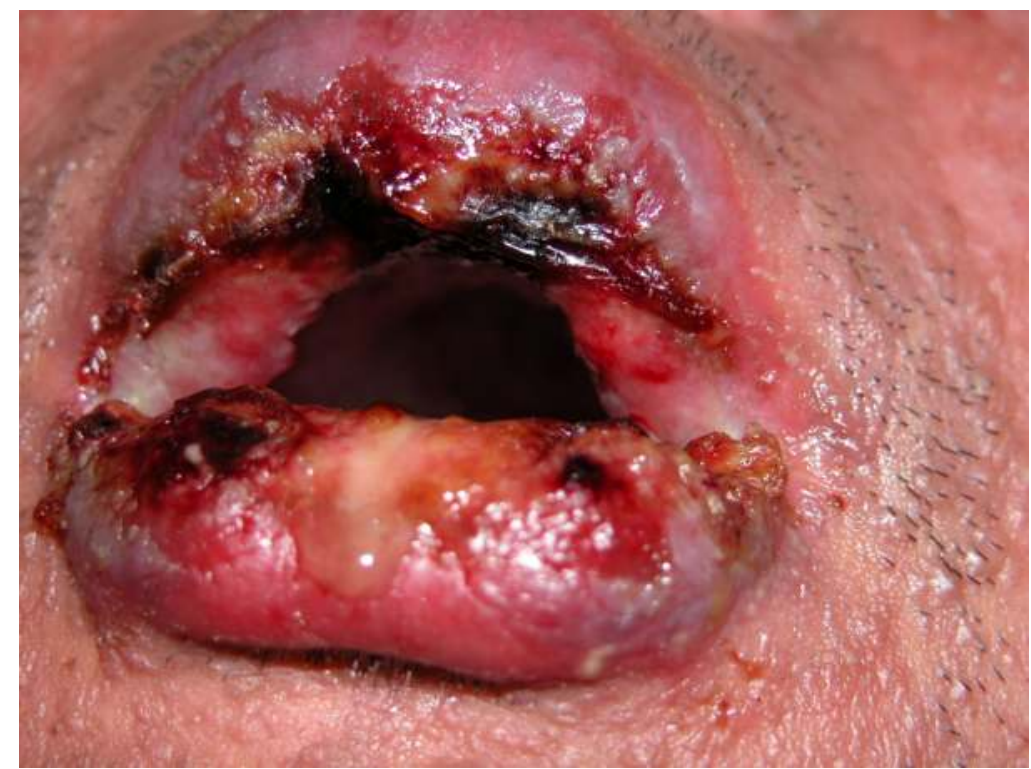

Figure 3. Oral mucositis in a patient with SJS depicted as sloughing, necrosis and crusting of the inner labial surfaces.

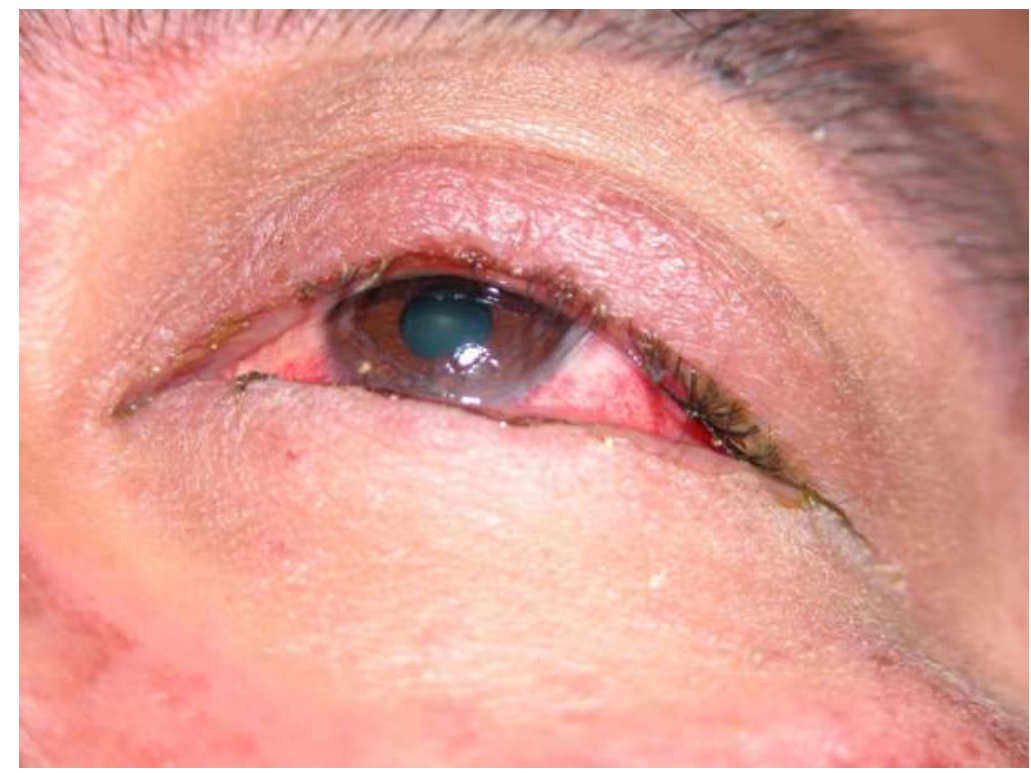

Figure 4. Purulent conjunctivitis in a patient with SJS accompanied by pseudomembrane formation, which results from sloughing of conjunctival and corneal surfaces. 


\begin{tabular}{lc}
\hline Severe Cutaneous Adverse Reactions & $\begin{array}{c}\text { Severe Cutaneous } \\
\text { Adverse Reactions }\end{array}$ \\
\hline Age $>40$ years & 1 \\
Presence of malignancy & 1 \\
Heart rate $>120 / \mathrm{min}$ & 1 \\
TBSA involved $>10 \%$ & 1 \\
Serum urea $>10 \mathrm{mmol} / \mathrm{L}(28 \mathrm{mg} / \mathrm{dL})$ & 1 \\
Serum glucose $>14 \mathrm{mmol} / \mathrm{L}(252 \mathrm{mg} / \mathrm{dL})$ & 1 \\
Serum bicarbonate $<20 \mathrm{mmol} / \mathrm{L}(20 \mathrm{mEq} / \mathrm{L})$ & 1 \\
\hline SCORTEN & Mortality $(\%)$ \\
\hline $0-1$ & 3.2 \\
2 & 12.1 \\
3 & 35.3 \\
4 & 58.3 \\
$\geq 5$ & 90 \\
\hline
\end{tabular}

Table 1. SCORTEN

\subsection{Pathogenesis}

SJS/TEN results from the T- and NK-cell mediated extensive apoptosis of keratinocytes. The pharmaco-immune (p-i) concept, the mechanism by which the drug binds directly with the $T$ cell receptor (TCR) causing activation of proapoptotic pathways. Granulysin is the major mediator of apoptosis in SJS/TEN. Apoptosis is also mediated through involved Fas-FasL interaction, and the release of granzyme and perforin.

\subsubsection{The pharmaco-immune ( $p$-i) concept}

It is generally accepted that in SJS/TEN, the parent drug binds directly and non-covalently to the MHC and the TCR of primed effector and memory T cells [45]. Naïve T cells are not sufficiently stimulated by a p-i drug and additional signals are required [46]. T cells may be primed by infection or autoimmune disease resulting in high cytokine levels such as IL-2 and IFN- $\gamma$ resulting in increased expression of MHC and costimulatory molecules. This may provide an explanation for the increased incidence of drug hypersensitivity in inflammatory and infectious diseases. The drug may also bind to toll-like receptors resulting in the expression of costimulatory molecules by dendritic cells. For drugs such as cotrimoxazole, lamotrigine, and carbamazepine, the p-i concept may not be the sole mechanism involved; metabolites may also play a role through haptenization [47]. 


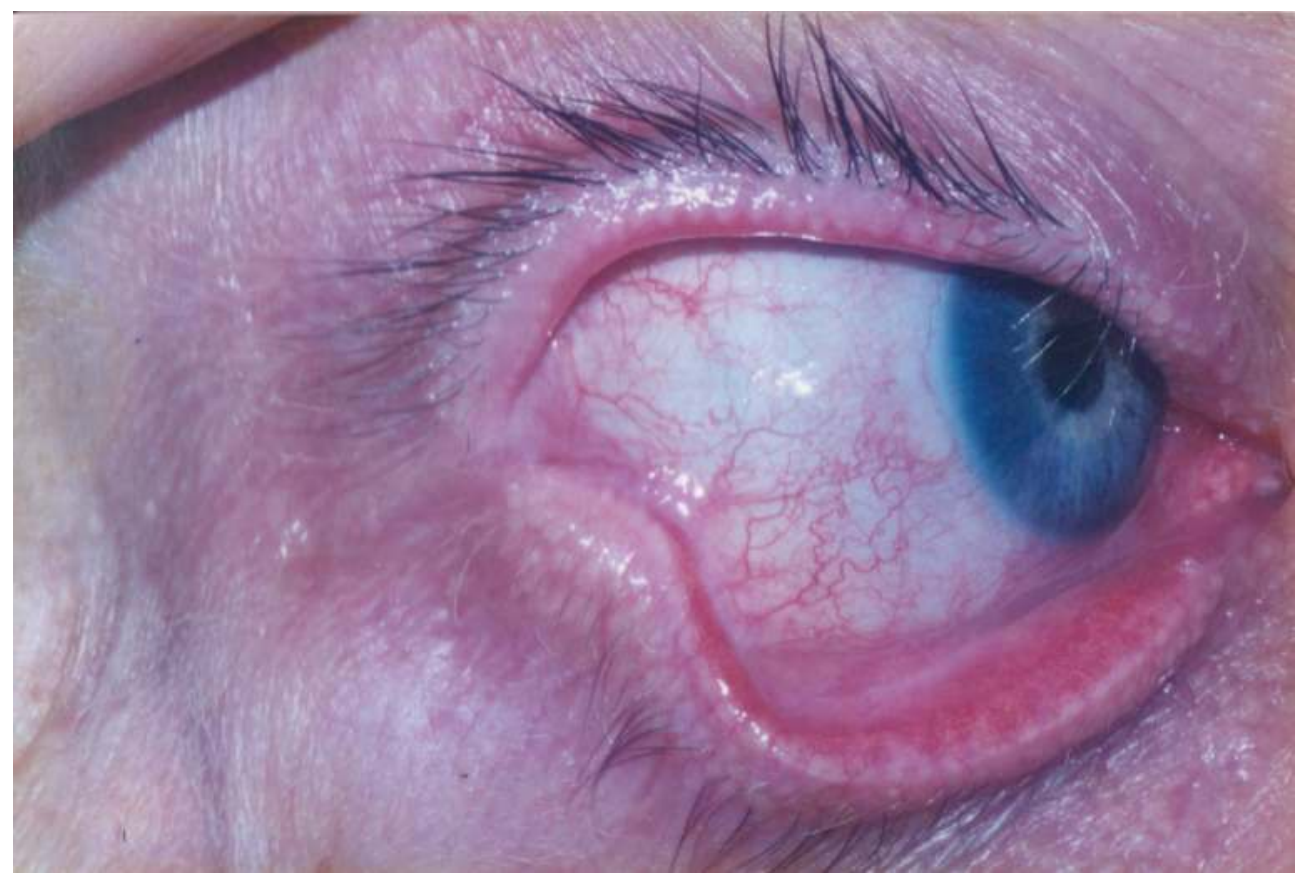

Figure 5. Cicatrization of the bulbar and palpebral conjunctival surfaces with resultant symblepharon formation, shortening of the fornix, and distichiasis.

\subsubsection{Granulysin}

A recent study by Chung et al using global gene expression profiling showed that granulysin RNA was the most significant cytotoxic molecule expressed in blister cells from patients with SJS/TEN. Granulysin protein concentrations were 2-4 times higher than perforin, granzyme B, and FasL and depleting granulysin reduced cytotoxicity [48]. Granulysin is a cationic cytolytic protein produced by CTL, NK and NKT cells [49]. The 15-kDa-precursor form, found in blister fluid, induced skin necrosis when injected into mice and exhibited significant cytotoxicity in vitro. This contrasted with the minimal cytotoxicity induced by perforin, granzyme B, and FasL [48]. Granulysin is also a proinflammatory molecule that causes an increase in the expression of chemokines (RANTES/CCL5, MCP-1, MCP-3, MIP-1 $\alpha /$ CCL3) and cytokines (IL-1, IL-6, IFN- $\alpha$ ) resulting in the recruitment of T cells, monocytes and other inflammatory cells [50].

\subsubsection{Fas-FasL, perforin/ granzyme and TNF pathways}

Viard et al, showed that the binding of FasL to Fas expressed on the surface of keratinocytes resulted in their apoptosis [51]. The cytoplasmic death domain of Fas undergoes conformational changes and trimerization upon recognition of FasL. This results in the recruitment of the Fas-associated death domain (FADD), which binds to procaspase 8 resulting in triggering 
of the caspase cascade and apoptosis. The source of the FasL is unclear. Viard et al showed that the FasL was is present on the surface of keratinocytes and in the serum of patients with TEN but not on the surface of keratinocytes or in the serum of patients with maculopapular exanthems and normal controls [51]. A further study demonstrated that FasL was not constitutively expressed on the surface of keratinocytes but are transported to the cell membrane after damage to the keratinocyte [52]. Abe et al, however, found that the source of FasL was PBMCs and not keratinocytes [53].

Nassif et al showed that mononuclear cells from blister fluid induce cytotoxicity via perforin and granzyme B [54]. This cytotoxicity was blocked by inhibiting perforin/granzyme but not by inhibiting Fas. Perforin and granzyme are proteins stored in the granules of CTLs. Upon recognition of a target cell, the CTL releases perforin, which create 16-nm channels in the target cell membrane. Granzyme B, a protease passes through these channels to activate the caspase cascade. The loss of $T$ regulatory cell function in the acute stage of SJS/TEN may further contribute to the epidermal damage caused by effector $\mathrm{T}$ cells [55].

Posadas et al, showed that both Fas-FasL and perforin/granzyme pathways may be involved in SJS/TEN. They found a direct correlation between disease severity and levels of perforin and granzyme B in patients with maculopapular exanthems, SJS and TEN. FasL was detected in the PBMCs and blister fluid of patients in SJS and TEN but not in those in maculopapular exanthema, suggesting that Fas-FasL is involved in more severe reactions [56].

Nassif et al, also showed a potential role for cytokines in the pathogenesis of SJS/TEN. He found elevated levels of IFN- $\gamma$, soluble TNF, IL-10, soluble FasL in the blister fluid of TEN patients. Although they disputed the central role of FasL, they hypothesised that drug specific CTLs secrete IFN- $\gamma$, which activates keratinocytes to produce TNF, a cytokine that upregulated MHC class I molecules. This increases exposure of keratinocytes to CTL resulting in perforin/ granzyme-mediated apoptosis. IL-10 serves to downregulate the inflammatory reaction [57].

More recently, TRAIL (TNF related apoptosis inducing ligand) and TWEAK (TNF-like weak inducer of apoptosis) were shown to be present in blister fluid from TEN patients [36]. They are released by CD1a and CD14 cells and initiate apoptosis of keratinocytes in a MHC-class Iindependent manner.

\subsection{Risk factors for SJS/TEN}

\subsubsection{Genetic susceptibility}

It was observed in the 1990s that the most commonly offending drugs varied among different ethnic populations. In Western countries, the most commonly implicated agents of SJS/TEN were NSAIDs and sulphonamides [17]. In contrast, carbamazepine was found to be the leading cause of SJS/TEN in Southeast Asian countries, including India, Malaysia, Singapore, Taiwan and Hong Kong [58]. Interestingly, carbamazepine in Western countries causes more cases of DIHS than SJS/TEN. Allopurinol is also a frequent case of SJS/TEN and DIHS but does not appear to have a racial bias [59]. 
The most striking genetic association was detected in a cohort of Han Chinese in Taiwan, where the $H L A-B^{*} 1502$ allele was found in $100 \%$ of the 44 patients with carbamazepineinduced SJS/TEN and only 3\% of the carbamazepine-tolerant individuals; OR 2504 [12649522] [60]. These findings were replicated in an extended cohort of subjects of Chinese descent originating from separated geographic areas of China, Taiwan, and the United States [61]. This association with carbamazepine-induced SJS/TEN, however, was not found in individuals with European [62] and Japanese ancestries [63], respectively, and therefore the allele appears relevant in the context of ethnicity. In a recent study comprising 12 patients of Northern European ancestry with carbamazepine-induced SJS/TEN, 5 (42\%) carried the HLA-A*3101 allele, as compared with $10(4 \%)$ of the 257 control subjects; OR 25.93 [4.93-116.18] [64]. The results of this study are yet to be replicated in other cohorts of subjects with Northern European ancestry. In a Japanese study, The HLA$A^{*} 3101$ allele was found in 5/6 (83.3\%) carbamazepine-induced SJS/TEN compared to 47/376 (12.5\%) carbamazepine-tolerant patients; OR 33.9 [3.9-295.6]. Larger patient sample sizes are required to confirm this association in the Japanese where the allele frequency is $9 \%$ [65]. Interestingly the $H L A-A^{*} 3101$ allele was shown to be associated with maculopapular exanthem (OR 17.5 [4.6-66.5]) but not SJS/TEN in a Han Chinese population [66].

A study comprising a Han Chinese cohort in Taiwan demonstrated the presence of the HLA$B^{*} 5801$ allele in all 51 patients with allopurinol-induced SCAR (21 with TEN, 30 with DIHS) compared with only 15\% (20/135) in allopurinol-tolerant subjects; OR 580.3 [34.4-9780.9] [67].

The role of these HLA alleles in the pathogenesis of SCAR is unclear. Certain HLA alleles may bind to particular drugs more robustly than other alleles. Furthermore, the binding of the drug in SJS/TEN is MHC class I restricted, which is consistent with the prominent role of CD8 cells in the pathogenesis of the disease. If an allele has a functional effect that may play a role in the pathogenesis of disease, this association will be consistently observed across different populations. The differences observed between the Chinese and European studies may be partly explained by the fact that pharmacogenetic studies are likely to yield positive results when conducted in a population with a high frequency of such an allele [69]. The risk of disease from a genetic polymorphism is influenced by its prevalence. The $H L A-B^{*} 1502$ allele frequency is 4.8 to $12.8 \%$ in Southeast Asians compared to $0-0.1 \%$ observed in Northern Europeans [58]. For instance, $H L A-B^{*} 1502$ is of low prevalence in Caucasians and hence, if it is a true susceptibility allele, a very large sample size is required in this population to detect a significant odds ratio of sufficient power. In contrast, the allele frequency of $H L A-A^{*} 3101$ is $2-5 \%$ in Northern Europeans [70] and the sample size required to demonstrate an association in a sufficiently powered study is less than that for the $H L A-B^{*} 1502$ allele. The $H L A-B^{*} 5801$ allele, in contrast to $H L A-B^{*} 1502$ is more evenly distributed among different racial groups [59] and hence, associations, albeit weaker, have been demonstrated in other ethnic groups such as the Southern Japanese [63] and in whites (OR 80 [34-157]) [68].

Another explanation is that $H L A-B^{*} 1502$, is a marker of a true disease contributing allele through strong linkage disequilibrium, which varies between populations. In other words, the same high-risk allele may have a different pattern of association with marker alleles and therefore $H L A-B^{*} 1502$ is in strong linkage disequilibrium in the Han Chinese population, but 
not in a European population. It is also plausible is that SJS/TEN is a polygenic disorder, with many susceptibility and protective alleles in genes involved in the pathogenesis of the disease. Polymorphisms in the proapoptotic gene Fas- $L$ [71], the toll-like receptor 3 gene [72], and in the IL-4 receptor/IL-13 signalling pathway [73] have all been recently described in a Japanese study. Such alleles may also vary in different populations.

The FDA and Health Canada have issued warnings for carbamazepine stating that persons with ancestry in genetically at-risk populations should be screened for the presence of $H L A$ $B^{*} 1502$ prior to initiating treatment [74]. Genetic screening for $H L A-B^{*} 1502$ in a high risk population such as the Han Chinese has a $100 \%$ sensitivity and $97 \%$ specificity and its presence confers a $7.7 \%$ positive predictive value for carbamazepine-induced SJS/TEN whereas its absence has a $100 \%$ negative predictive value [58]. The odds ratio in test-positive Chinese patients to test-negative patients of having carbamazepine-induced SJS/TEN is $>3200$. Although $3 \%$ of patients who are test-positive may never develop the disease, the serious and life-threatening consequences of developing SJS/TEN and the availability of alternative drugs, justifies its exclusion from these individuals. The lack of prevalence of $H L A-B^{*} 1502$ in nonAsian populations may limit its cost effectiveness as a screening tool in these populations and cannot be currently recommended. A recent study demonstrated the benefit of genetic screening; in a Taiwanese population, screening for the $H L A-B^{*} 1502$ allele resulted in no cases of SJS/TEN in 4501 patients who were negative for the allele [75]. The authors concluded that this would have prevented 10 cases of SJS/TEN. Despite the FDA recommendations, screening is not routinely performed partly because of the lack of availability of cost effective and rapid methods of detection [76]. Susceptibility alleles can be identified by high resolution sequence based HLA typing after a $20 \mathrm{ml}$ sample of blood is collected in an ADC tube. However, this highly specialized and relatively expensive diagnostic technique is limited to a small number of laboratories that focus on transplantation medicine and may be limited by longer turnaround times of up to 3-4 weeks. Many laboratories have now developed high resolution genetic testing using a sequence-specific primer assay method for the detection of this allele from samples collected in either 7-10 $\mathrm{ml}$ of whole blood (EDTA tube) or buccal swabs (provided by the testing laboratory). The assay can be performed within 3-4 hours. Such a strategy is not novel and has been very successful in virtually abolishing the incidence of HLA-B*5701associated abacavir hypersensitivity in HIV-infected patients [77]. Multiplexed PCRs can be utilized to assess multiple alleles.

It is important to note that the $H L A-B^{*} 1502$ allele does not predispose to carbamazepineinduced DIHS, maculopapular eruptions or other adverse reactions and continued vigilance for the symptoms of SCAR needs to be maintained if treatment is commenced [61].

Currently, there is no recommendation for genetic screening prior to the commencement of allopurinol therapy. Although such a strategy is plausible, studies are required to determine the benefits of screening for the $H L A^{*} 5801$ allele in at risk populations.

\subsubsection{Diseases}

The EuroSCAR study showed that HIV infection conferred the highest risk of SJS/TEN; multivariate relative risk (mvRR) 12 [2.4-59]. Other disease associations included collagen 
vascular disease mvRR 2.2 [0.9-5.0], recent malignancy mvRR 2.7 [1.3-5.7], recent radiotherapy mvRR 2.1 [0.5-9.0], or acute infection in the past 4 weeks [1.2-2.3] [11].

\subsubsection{Pharmacokinetics}

The EuroSCAR study revealed an increased risk of SJS/TEN at higher doses of allopurinol; adjusted odds ratio (OR) 36 [17-76] for doses $\geq 200 \mathrm{mg}$ daily compared with an adjusted OR 3.0 [1.1-8.4] for doses $<200 \mathrm{mg}$ daily [78]. This study also revealed that the risk was mostly confined to short-term use ( $\leq 8$ weeks, unadjusted OR $261[36-\infty])$. Allopurinol should be commenced at a dose of $100 \mathrm{mg}$ daily and increased by $100 \mathrm{mg}$ increments until the desired serum uric acid level is attained. Previous reports have shown that allopurinol is commenced at inappropriate doses [79] and that higher doses are associated with an increased incidence of acute events [80]. It is likely that the rapid accumulation of the chemically reactive metabolite oxypurinol when higher doses of allopurinol are commenced increases the risk of SJS/TEN [81],[82]. This drug accumulation hypothesis is further supported by the 4.7 fold increased incidence of allopurinol-induced SCAR in renal insufficiency [83]. The established indications for allopurinol are treatment of hyperuricemia associated with chronic gout, acute uric acid nephropathy, recurrent uric acid stone formation, enzyme disorders of purine metabolism, and in the management of tumour lysis. Allopurinol is not indicated in the majority of patients with asymptomatic hyperuricemia [84]. However, allopurinol is inappropriately prescribed in up to $86 \%$ of cases [85]-[87]. A comparison of allopurinol exposure between the SCAR (1989-1993) and EuroSCAR (1997-2001) studies showed a 2-3 fold increase in exposure for both patients and control subjects, which may be attributed to the increased prescribing of the drug for the treatment of asymptomatic hyperuricemia. The authors of the EuroSCAR study postulate that up to 48 of the 56 cases of allopurinol-induced SJS/TEN could have been prevented if the treatment guidelines for prescribing allopurinol were followed.

Lamotrigine when commenced at high doses can also overwhelm the detoxifying capacity resulting in an increased risk of SJS/TEN and DIHS [88]. The incidence has reduced significantly as a result of the now conventional practice of gradually titrating the dose [89]. Coadministration of certain drugs can predispose to SCAR by competition for the same enzymebinding site. Reactions to lamotrigine are more common when given in combination with valproic acid as the addition of valproic acid inhibits the clearance of lamotrigine by competing for glucoronic acid conjugation [90].

The role of slow acetylation phenotypes of $\mathrm{N}$-acetyltransferase was thought to confer susceptibility of sulphonamide-induced SJS/TEN in two small studies [91],[92] but this needs confirmation in larger studies.

\subsection{Diagnosis}

A presumptive diagnosis of SJS/TEN is made clinically and is confirmed with a skin biopsy (Figs. 6 \& 7). Early lesions demonstrate vacuolar alteration and scattered necrotic keratinocytes in the epidermal layers at the level of the stratum spinosum and the basal cell layer. Later, full thickness epidermal necrosis is evident, which eventuates in the formation of subepidermal 
bullae [93]. The mononuclear predominantly $\mathrm{T}$ cell dermal infiltrate is generally sparse but dense infiltrates can also be present. Quinn et al, has shown an extensive infiltrate was associated with a $71 \%$ mortality rate, a moderate infiltrate with a $53 \%$ mortality, and a sparse infiltrate with a $27 \%$ mortality, respectively [94]. A fresh sample for direct immunofluoresence (DIF) reveals an absence of immunoglobulin and complement deposition. The cornified layer remains intact. Immunohistochemistry usually reveals a predominance of CD8 cells in the epidermis and CD4 cells in the dermis. A fresh sample for direct immunofluoresence (DIF) reveals an absence of immunoglobulin and complement deposition.

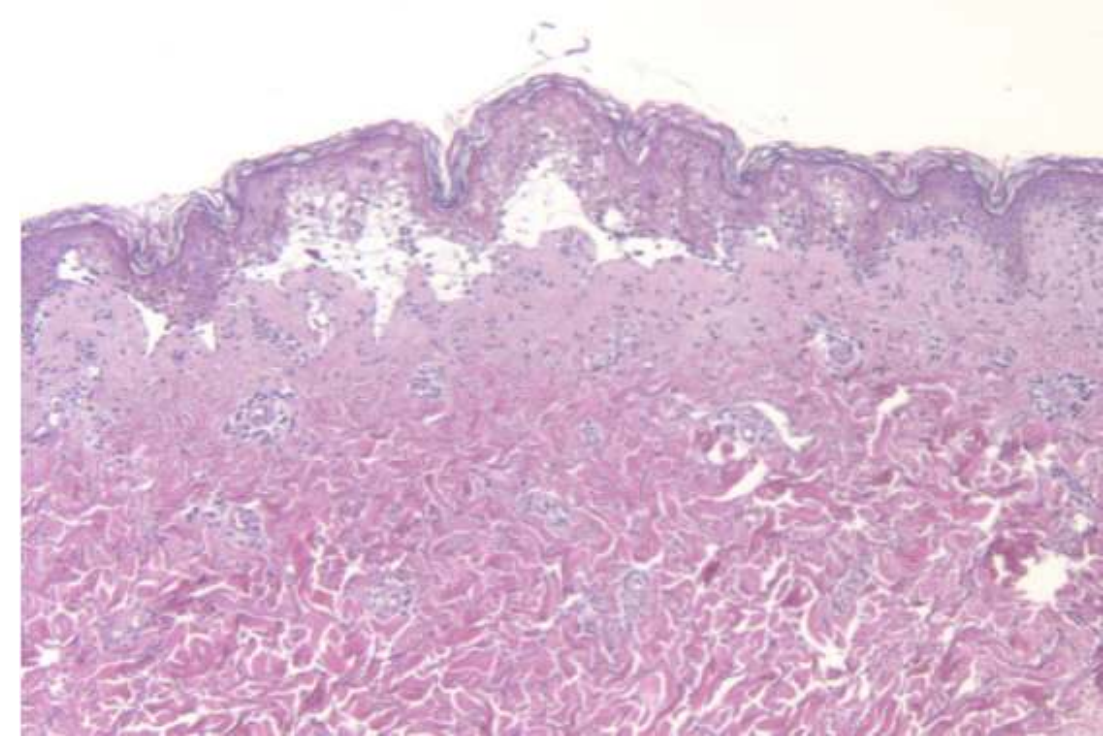

Figure 6. Low power view of a skin biopsy from a patient with SJS demonstrates separation of the epidermis from the dermis at the level of the stratum spinosum and basal cell layer resulting in the formation of subepidermal bullae (Hematoxylin-eosin, original magnification $\mathrm{x} 40$ ).

Cultures on blood, wounds and mucosal lesions should be performed to evaluate for superinfection. Serology may be performed for Mycoplasma pneumoniae if indicated.

A recent pilot study showed that serum granulysin levels may be raised early in the course of disease but rapidly wanes with progression of disease [95]. Further studies are required to determine whether this assay will prove to be a useful early diagnostic test for SJS/TEN.

\subsection{Allergy testing}

Skin tests and oral challenges are contraindicated in SJS/TEN because of the risk of inducing a recurrence of disease. Patch testing has not been investigated extensively. The biggest cohort comprised 22 patients and showed a poor sensitivity of only 9\% [96]. Lymphocyte transformation tests (LTTs) assesses the proliferation of the patient's peripheral blood T cells cultured 


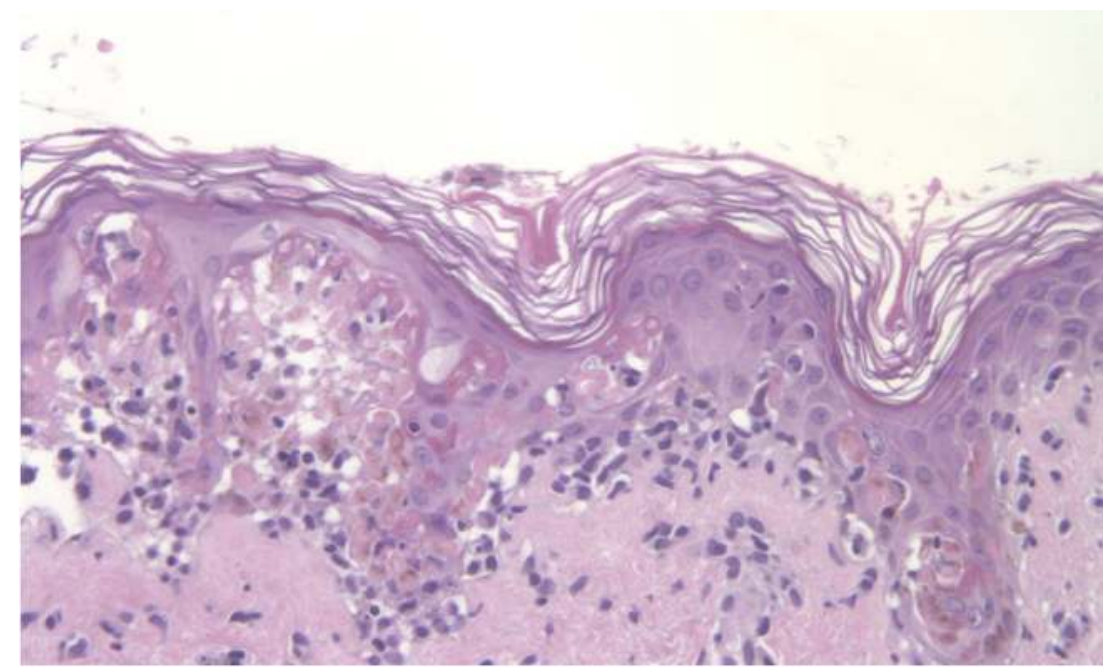

Figure 7. High power view of a skin biopsy from a patient with SJS shows necrosis of keratinocytes, and vacuolar degeneration of the basal cell layer. A sparse lymphocytic infiltrate is present at the dermoepidermal junction and displays satellitosis or clustering around dying basal cells (Hematoxylin-eosin, original magnification x200).

in the presence of a suspected drug for 6 days by measuring the incorporation of ${ }^{3} \mathrm{H}$-thymidine during DNA synthesis. The result is expressed as a stimulation index, which is the ratio of cell proliferation with antigen and without antigen. The sensitivity of LTTs in SJS/TEN is greatly improved if the test is performed within 1 week of the onset of disease but becomes negative by 6 weeks [97]. This may be attributed to loss of regulatory $\mathrm{T}$ cell function in the acute phase, which is then restored upon recovery [55]. Recently, a new cytotoxicity assay combining the measurement of expression of the degranulation marker, CD107a, using flow cytometry and the release of the serine protease, granzyme B by Elispot after incubating the patient's peripheral blood mononuclear cells with the suspected drug for 3 days [98]. The test has very good specificity with all of the 16 controls having a negative test and good sensitivity with 10 of the 12 patients having a positive result. One role of these in vitro tests is to determine the culprit drug when more than one drug is suspected.

\subsection{Differential Diagnosis}

SJS/TEN is differentiated from other conditions on the basis of the acute onset of disease, the presence of targetoid and vesiculobullous lesions, sloughing of the epidermis, severe mucosal involvement, the histologic finding of full thickness epidermal necrosis, and a negative DIF. In EM major, erosive mucous membrane involvement is present but in contrast to SJS, the patient has typical target lesions mainly affecting the extremities and it is often induced by acute or recurrent HSV infection. The clinical manifestations of drug-induced maculopapular exanthems (MPE) are variable and often polymorphic and lesions may have a target-like appearance. Fever may be present but mucosal involvement is absent. The histopathology 
typically shows an interface dermatitis with hydropic degeneration of the basal cell layer [99]. Some exanthems may progress to more severe reactions such as SJS/TEN or DIHS. Generalized bullous fixed drug eruption (GBFDE) features large brownish violaceous patches upon which flaccid blisters arise. These blisters affect only a small percentage of the TBSA. Mucosal involvement is rare and fever is absent. Most patients report a history of a similar local reaction or fixed drug eruption [100].

Staphylococcal scalded skin syndrome (SSSS) usually affects children under the age of 5 years and patients present with fever, erythema and painful skin, followed by blistering, which is typically accentuated in areas of friction and around orifices [101]. SSSS is caused by the systemic distribution of epidermolytic toxins produced by certain strains of Staphylococci. These toxins cause separation at the level of the stratum granulosum, the upper layer of the epidermis, resulting in very superficial detachment of the skin and blistering[102]. Mucous membrane involvement is rare. The condition usually but not always follows local or systemic staphylococcal infection [103]. Adults are less susceptible as improved renal function allows for better clearance of the toxins. However SSSS has been described in adults who are immunosuppressed or in renal failure [101]. Toxic shock syndrome (TSS) is caused by elaboration of toxins produced by Staphylococcus aureus and Streptococcus pyogenes that act as superantigens, which bind to the variable regions of $\beta$ chains of antigen receptors on subsets of $\mathrm{T}$ cells and cross-link them to the MHC molecules of antigen-presenting cells [104]. This results in activation of large numbers of $\mathrm{T}$ cells (5-30\%) and the massive release of cytokines including IL-2, TNF, lymphotoxin and IL-1 $\beta$. TSS is characterised by fever, diffuse red macular rash, hypotension and involvement of $\geq 3$ organs: renal failure, hepatitis, thrombocytopenia, encephalopathy, mucous membrane hyperemia, gastrointestinal involvement with vomiting and diarhhoea. Desquamation occurs after 1-2 weeks and predominantly affects the palms and soles. Approximately $50 \%$ of cases are menstrually related due to the prolonged application of absorbent tampons. Notably, $50 \%$ of cases of TSS are not associated with menstruation. Nonmenstrual cases of TSS usually complicate the use of barrier contraceptives, surgical and postpartum wound infections, burns, cutaneous lesions, osteomyelitis, and arthritis. Although most cases of TSS occur in women, about $25 \%$ of non-menstrual cases occur in men.

Autoimmune bullous diseases need to be considered in the differential diagnosis of SJS/ TEN. These conditions, in contrast to SJS/TEN, usually have a chronic course and are characterized by acantholysis on histopathology and immunoglobulin deposition on DIF. Drug-induced linear IgA bullous dermatosis can produce an acute extensive eruption of target-like lesions, pruritic urticarial plaques and tense bullae on the trunk and limbs [105]. Vancomycin is the most commonly implicated drug. In contrast to SJS, mucosal lesions are rare and DIF shows linear deposition of $\operatorname{IgA}$ at the basement membrane zone. Paraneoplastic pemphigus (PNP) is a chronic disease characterized by severe and intractable oral mucositis and a generalized polymorphous blistering eruption in association with an occult or overt malignancy, especially, lymphoma and Castleman's disease [106], [107]. Conjunctivitis is common and respiratory and gastrointestinal surfaces may be involved. DIF shows deposition of IgG and complement (C3) within the epidermal intercellular spaces and along the epidermal basement membrane. Drug-induced pemphigus is 
usually triggered by thiol drugs in genetically susceptible individuals [108]. These drugs, such as penicillamine, captopril and enalapril, directly interact with the epidermis and cause acantholysis and a superficial blistering eruption with crusts and erosions without mucosal involvement resembling pemphigus foliaceus (PF) [109]. However, in contrast to $\mathrm{PF}$, which is mediated by antibodies against desmoglein-3, DIF may be negative in druginduced pemphigus. Non-thiol drugs can cause disease indistinguishable from pemphigus vulgaris (PV). These cases of drug-triggered pemphigus, like PV are chronic with autoantibodies formed against desmoglein-3 [110]. Hence a flaccid blistering eruption with mucosal involvement occurs, and DIF shows IgG and C3 deposition in the epidermal intercellular spaces. Bullous pemphigoid (BP) is a chronic disease that is typified by a tense bullous eruption that primarily affects individuals in the fifth through seventh decades of life. Drugs, especially diuretics such as furosemide and spironolactone, can induce BP [111] and should be considered when the condition occurs in a young patient and the course is more abrupt [112]. Unlike in SJS/TEN, fever is absent, mucosal lesions are usually absent, and DIF reveals IgG and C3 linear deposition along the epidermal basement membrane [113].

Acute graft versus host disease (AGVHD) shares many of the same clinical, pathologic and immunologic features as SJS/TEN. Both conditions are mediated by cytotoxic T cells, which results in epidermal necrosis and keratinolysis [114],[115]. Furthermore, bone marrow transplantation (BMT) patients receive medications that can trigger SJS/TEN. AGVHD generally occurs 4 weeks after stem cell transplantation. Patients describe a sensation of skin pain and itching followed by a morbilliform rash that in severe cases becomes generalized with diffuse areas of epidermal necrosis [116]. Mucositis is usually present. AGVHD frequently begins acrally and spreads proximally in contrast to TEN, which begins on the trunk and spreads distally. Also, the early exanthem of AGVHD has a folliculocentric distribution [117].

AGEP is characterized by fever and as the disease progresses, widespread erosions mimicking SJS/TEN may be evident [118]. Mucous membrane involvement is unusual and if present is mild.

SJS/TEN, Stevens-Johnson syndrome/toxic epidermal necrolysis; EM, erythema multiforme; MPE, maculopapular exanthem; GBFDE, generalized bullous fixed drug eruption; SSSS, staphylococcal scalded skin syndrome; TSS, toxic shock syndrome; PNP, paraneoplastic pemphigus; AGVHD, acute graft versus host disease; AGEP, acute generalized exanthematous pustulosis

\subsection{Treatment}

\subsubsection{Supportive care}

Immediate discontinuation of the culprit drug is mandatory to reduce mortality [119]. As the management of TEN is similar to that of extensive burns, a transfer to a burns unit reduces morbidity and mortality. The largest trial showed a mortality rate of $29.8 \%$ after transfer to a burns unit compared to $51.4 \%(\mathrm{p}<.05)$ after 7 days [120]. The unit has expertise in providing 


\begin{tabular}{|c|c|c|c|c|c|c|}
\hline Bullous disease & Fever & Mucositis & Rash & DIF & Onset & $\begin{array}{l}\text { Other notable } \\
\text { features }\end{array}$ \\
\hline SJS/TEN & + & + & $\begin{array}{l}\text { Erythroderma } \\
\text { Targetoid lesions } \\
\text { Vesicles, bullae } \\
\text { Erosions, detachment }\end{array}$ & - & Acute & $\begin{array}{l}\text { Starts on trunk, } \\
\text { proximal upper limbs } \\
\text { and face and then } \\
\text { spreads }\end{array}$ \\
\hline EM Major & + & + & $\begin{array}{l}\text { Acral } \\
\text { Target lesions }\end{array}$ & - & Acute & $\begin{array}{l}\text { HSV-induced } \\
\text { recurrences }\end{array}$ \\
\hline Drug-induced MPE & $+/-$ & - & $\begin{array}{l}\text { Variable } \\
\text { Pleomorphic }\end{array}$ & - & Acute & $\begin{array}{l}\text { May progress to SJS or } \\
\text { DIHS }\end{array}$ \\
\hline GBFDE & - & - & $\begin{array}{l}\text { Brown patches } \\
\text { Large bullae }\end{array}$ & - & Acute & $\begin{array}{l}\text { Antecedent local } \\
\text { reaction } \\
\text { Small \% TBSA }\end{array}$ \\
\hline SSSS & + & - & $\begin{array}{l}\text { Erythroderma } \\
\text { Skin tenderness } \\
\text { Periorificial crusting }\end{array}$ & - & Acute & $\begin{array}{l}\text { Children under } 5 \\
\text { Adults with chronic } \\
\text { renal failure and on } \\
\text { immunosuppressive } \\
\text { therapy }\end{array}$ \\
\hline TSS & + & + & $\begin{array}{l}\text { Diffuse red macular } \\
\text { rash } \\
\text { Desquamation of } \\
\text { palms and soles }\end{array}$ & - & Acute & $\begin{array}{l}\text { Hypotension } \\
\text { Multiple organ failure }\end{array}$ \\
\hline $\begin{array}{l}\text { Drug-induced } \\
\text { linear IgA dermatosis }\end{array}$ & - & - & Tense bullae & + & Acute & $\begin{array}{l}\text { Vancomycin } \\
\text { Pruritus }\end{array}$ \\
\hline PNP & - & + & $\begin{array}{l}\text { Polymorphous } \\
\text { Bullae }\end{array}$ & + & Gradual & \\
\hline $\begin{array}{l}\text { Drug-induced } \\
\text { pemphigus }\end{array}$ & - & - & $\begin{array}{l}\text { Erosions } \\
\text { Crusts }\end{array}$ & + & Gradual & Thiol drugs \\
\hline $\begin{array}{l}\text { Drug-triggered } \\
\text { pemphigus }\end{array}$ & - & + & $\begin{array}{l}\text { Mucosal erosions } \\
\text { Flaccid bullae }\end{array}$ & + & Gradual & Non-thiol drugs \\
\hline AGVHD & + & + & $\begin{array}{l}\text { Morbilliform rash } \\
\text { Bullae } \\
\text { Erosions, detachment }\end{array}$ & - & Acute & $\begin{array}{l}\text { Starts acrally and then } \\
\text { spreads }\end{array}$ \\
\hline AGEP & + & $+/-$ & $\begin{array}{l}\text { Small nonfollicular } \\
\text { pustules } \\
\text { Erythroderma }\end{array}$ & - & Acute & \\
\hline
\end{tabular}

Table 2. The differential diagnosis of SJS/TEN 
analgesia, maintaining fluid and electrolyte balance and preventing and treating superinfection. It has been recently noted that in contrast to burns, TEN affects the epidermis and hence fluid and electrolyte requirements are less than for burns of the same extent [121]; initial administration of $2 \mathrm{ml} / \mathrm{kg} / \%$ TBSA is usually sufficient [122]. Additional nutritional requirements result from loss of nitrogen and energy from the wound exudate, the hypermetabolic response of TEN and sepsis and the promotion of wound healing. However, these requirements may lower than in burns, with one study in the paediatric population suggesting that that patients with TENS require $22 \%$ fewer calories per day than patients with burns. A formula was subsequently developed: calorie requirement = baseline weight $(\mathrm{kg}) \times 24.6+$ wound size (\%TBSA) $\times 4.1+940$ [123]. Enteral or total parenteral nutrition should be considered in patients unable to ingest food. Nasogastric feeding should be cautiously initiated because of gastrointestinal involvement from TEN and the difficulties in placing a nasogastric tube in the presence of a oropharyngeal involvement [124]. Room temperature should be adjusted to $30-32^{\circ} \mathrm{C}$ or heat-air body warmers should be used to prevent excessive caloric expenditure due to epidermal loss [25].

The optimal approach to wound management has not been determined and will therefore vary between specialty units. The contrasting measures of surgical debridement with whirlpool therapy to remove necrotic epidermis, and anti-shear wound care [125], in which detached skin is left in situ to act as a biological dressing [126], both have equivalent rates of reepithelialization and survival. Non-adherent nanocrystalline-containing gauzes are being increasingly used because of their broad antimicrobial effects [127],[128]. This obviates the need for topical silver sulphadiazine because of the strong association between sulphonamides and SJS/TEN. There is also a trend in the use of biosynthetic skin substitutes in place of porcine xenograft and human allograft cadaveric skin because of reduced pain and improved mobilization in elderly patients [129].

Prophylactic antibiotics are not advised as they predispose to the emergence of resistant organisms [121]. Hence, repeated cultures of the skin, blood and other sites guide the need for antibiotic therapy. Sterile handling and reverse-isolation procedures are essential in the prevention of nosocomial infection [130].

Ophthalmologic consultation is mandatory in SJS/TEN and the combination of aggressive lubrication, topical antibiotics, topical corticosteroids, and lysis of adhesions with a glass rod is implemented immediately but has only a modest effect on the long term ocular complications. Recently, the application of amniotic membranes has proved effective in preserving visual acuity and an intact ocular surface [37]. The benefit may be derived from creating a physical barrier between inflamed and denuded mucosal surfaces that minimizes the formation of adhesions. The membrane may also have antiinflammatory and antifibrotic effects [131].

Other supportive measures include hygienic mouthwashes and topical oral anaesthetics, and monitoring for urinary retention. 


\subsubsection{Corticosteroids}

The role of corticosteroids in the treatment of SJS/TEN is controversial. Corticosteroids given 48 hours or more prior to admission are associated with an increase incidence of infection, length of hospital admission, and mortality in children and adults [132]-[134]. A study in 1986 of 30 patients with TEN with an average TBSA involvement $>80 \%$ were equally divided into those receiving supportive care alone and those receiving dexamethasone at varying doses [135]. Although the incidence of sepsis was not significant different between the groups, the survival following onset of sepsis was less in the corticosteroid treated group. The use of corticosteroids doubled the rate of mortality (66\% versus 33\%). Corticosteroids do not prevent SJS/TEN from occurring and have no effect on arresting disease progression [136],[137]. A retrospective analysis of 281 patients from the EuroSCAR study found no benefit from corticosteroids or IVIg compared to supportive care alone.

The poor outcomes may have resulted from inadequate doses and the delay in the initiation of corticosteroid therapy. In a prospective study of 16 children with SJS in 1997, 10 received methylprednisolone $(4 \mathrm{mg} / \mathrm{kg} /$ daily) within 3 days of the onset of rash whilst 6 received supportive care only; corticosteroids were associated with decreased length of fever and duration of skin eruption [138]. The use of pulsed IV corticosteroids has been shown in retrospective reviews to reduce mortality [139]-[141]. The initiation of IV methylprednisolone 500-1000 mg/daily for 3-4 days may also prevent ocular complications of cicatrization and preservation of visual acuity [142]. The benefits of early pulsed therapy with IV corticosteroids need to be further evaluated in randomized control trials.

The current level of evidence suggests that high dose corticosteroids may be beneficial if commenced early in the course of disease with vigilant monitoring for emergence of infection. However, no definitive conclusion can be drawn from this current level of evidence and prospective trials with well defined protocols are required to define the role of corticosteroids in the treatment of SJS/TEN.

\subsubsection{Intravenous Immunoglobulin (IVIg)}

The rationale for the use of IVIg was based on its ability in vitro to block Fas and subsequently FasL-mediated apoptosis of keratinocytes [51]. The beneficial role of IVIg in SJS/TEN has been demonstrated in retrospective studies. The largest such study to date comprised 48 patients with TEN with a $44.8 \%$ mean TBSA recruited from centres across Europe and the United States. Treatment with IVIg resulted in a more rapid cessation of epidermal detachment and a survival rate of $88 \%$. The authors subsequently recommended a dose of $1 \mathrm{~g} / \mathrm{kg} /$ daily for 3 days [143]. Studies have also demonstrated benefit when investigators have compared the rates of mortality following the use of IVIg with the pre-treatment estimate using SCORTEN. For example, Campione et al, found that $400 \mathrm{mg} / \mathrm{kg} /$ daily for 5 days of IVIg resulted in a mortality rate of $10 \%$, significantly lower that the $35 \%$ predicted using SCORTEN [144]. Metry et al, showed that the benefit of IVIg extended to the paediatric population [145].

In 2006, a retrospective study found that the use of IVIg at a total dose of $2.8 \mathrm{~g} / \mathrm{kg} /$ daily in 23 patients resulted in a marked difference in mortality compared to 8 patients who received 
supportive therapy alone despite the absence of a difference in SCORTEN between the two groups. The mortality rate was $26 \%$ in the patient group receiving IVIg and $75 \%$ in the group receiving supportive care only. This difference, however, was not statistically significant. A study by Yang et al, showed a lower than predicted mortality rate for patients given IVIg and corticosteroids and a higher than expected mortality rate for those receiving corticosteroids alone. This difference was not statistically significant [146].

Despite the initial preponderance of evidence favouring the use of IVIG in SJS/TEN, a few published reports have not demonstrated any benefit. Most of these studies comparing the use of IVIg with supportive care alone used doses less than the recommended 2-3 g/kg [147]-[150]. The largest restrospective analysis on the use of IVIg derived from the EuroSCAR study and published in 2008 included 109 patients with TEN, 136 with SJS/TEN overlap, and 134 with SJS found that IVIg administered at a dose of $1.9 \mathrm{~g} / \mathrm{kg}$ conferred an OR of 1.4 when compared to the use of supportive measures alone. This study involved the use of lower than recommended doses of IVIg and the patients from the IVIg group tended to have a greater TBSA involvement [151]. A controlled observational study in an intensive care unit in a French dermatology department of 34 patients who presented at a mean of 4.3 days after the onset of TEN revealed a higher mortality rate than that predicted by SCORTEN when $2 \mathrm{~g} / \mathrm{kg}$ of IVIg was administered within 2 days of admission [85].

Randomized control studies are required using sufficient doses of IVIg to characterize its benefit in not only reducing mortality but also arresting the rate of progression and hastening the rate of re-epithelialization. However, the evidence thus far, is not robust as an adjunctive immunomodulatory therapy in the treatment of SJS/TEN.

\subsubsection{C yclosporine}

Cyclosporine inhibits CD8 activation and subsequent release of granulysin, granzyme and perforin as well as inhibiting the proapoptotic effect of NF-kB. Several case and case series reports have shown arrest of disease progression and shorter time to re-epithelialization with doses varying from 3-10 mg/kg/daily for a period ranging from 8 days to several weeks [152] [153]-[161]. The study by Arevalo et al, showed that outcomes for 10 patients treated with cyclosporin was superior to 6 patients treated with cyclophosphamide and corticosteroids with respect to re-epithelialization, disease progression and death [157]. However, randomized control studies are required to better define its benefits, the appropriate dose and duration of therapy. Furthermore, no studies have been published to date evaluating the efficacy of using both IVIg and cyclosporine but may be worthwhile considering as different pathways involved in the pathogenesis of SJS/TEN are targeted.

\subsubsection{Plasmapheresis}

Plasmapheresis (PE) has been reported to be beneficial in several case reports and series in patients with TEN based on the principle that the drug, drug metabolite or cytotoxic mediator is removed from the circulation [162]-[165]. One report from Sweden showed no benefit from $\mathrm{PE}$ in eight patients compared with patients from other studies who received similar support 
care but without PE [166]. There is insufficient evidence at this stage to support the use of PE in preference to other adjunctive measures.

\subsubsection{Anti-TNF therapy}

TNF is thought to be upregulated in TEN and immunohistochemistry has demonstrated increased levels of TNF from 23 patients as compared with controls [167]. Thalidomide, a potent inhibitor of TNF, was found in a double blinded randomized placebo controlled trial to be lethal in 10 of 12 patients compared with 3 of 10 control subjects. The exact mechanism underlying these fatalities is unknown but the drug is firmly contraindicated in SJS/TEN.

Infliximab and eternecept has been shown to be beneficial in a small number of case reports [168]-[173]. The drug was usually administered late in the course of disease and therefore its benefit is not clear and requires case-control studies to further elucidate its role.

\subsubsection{N-acetylcysteine}

Strategies have been explored to overcome the diminished detoxifying capacity of abnormal inherent metabolic pathways evident in a proportion of patients with SJS/TEN. Administration of $\mathrm{N}$-acetylcysteine enhances the oxidant buffering capacity of glutathione, which enhances the detoxification of a range of drugs, as well as inhibiting NF- $\mathrm{kB}$. Two case reports have shown a beneficial response but larger studies are clearly required before it is readily applied in clinical practice [174],[175].

\subsubsection{Restricted use of related medications}

In addition to the restricted use of the same medication, structurally similar drugs should also be avoided. The aromatic anticonvulsants carbamazepine, phenytoin and phenobarbitol cross react with one another. Cross reactivity resulting in SJS/TEN can also occur across different classes of beta-lactam antibiotics, such as penicillins, cephalosporins and carbapenems [176]. Administration of a structurally related drug can also result in different reactions. One case report described a patient with ceftriaxone-induced TEN who developed immediate anaphylaxis following the administration of piperacillin/tazobactam [177].

The risk of SJS/TEN with structurally distinct agents within the same class of drug is less clear. For example, the cross reactivity between a priopionic acid NSAID and an enolic acid NSAID is unknown. The safest practice is to restrict all NSAIDs following NSAID-induced SJS/TEN.

\section{Drug induced hypersensitivity syndrome}

\subsection{Nosology}

The term hypersensitivity syndrome has been used for decades to describe a cutaneous drug reaction accompanied by involvement of internal organs. In 1938, Merritt and Putnam described a toxic reaction to phenytoin characterized by exfoliative dermatitis, fever and 
eosinophilia [178]. This was distinguished from those patients who developed a mild, morbilliform rash. Chaiken et al coined the term Dilantin hypersensitivity in 1950 to further characterize the systemic reaction described by Merritt and Putnam to also include lymphadenopathy and multivisceral involvement [179]. Saltzein in 1959 described a drug-induced lymphoma characterized by lymphadenopathy and diffuse skin nodules and plaques without internal organ involvement. [180]. The anticonvulsant hypersensitivity syndrome was named in 1988 by Shear and Spielberg to refer the similar cutaneous and systemic manifestations of idiosyncratic reactions to a range of anticonvulsant medications including phenytoin, phenobarbitol and carbamazepine [181]. In 1996, Bocquet et al introduced the term drug reaction with eosinophilia and systemic symptoms (DRESS) to distinguish it from drug-induced pseudolymphoma and other drug reactions that are not associated with eosinophilia [182]. Finally, Shiohara et al proposed the term drug induced hypersensitivity syndrome (DIHS) to include patients who may not have marked eosinophilia but have other evidence of leukocyte abnormalities, internal organ involvement and evidence of HHV-6 reactivation [183],[184].

\subsection{Epidemiology}

The incidence of DIHS is estimated to be between 1 in 1000 and 1 in 10000 to phenytoin [185]. The true incidence remains to be determined because of the variable presentations and the lack of universally accepted criteria. The JSCAR and RegiSCAR studies will provide more accurate reporting on the basis of stringent criteria. Preliminary data from the RegiSCAR study suggests that it affects males and females equally with a mean age of 47.4 years (range 3-84 years) [186].

\subsection{Etiology and clinical features}

Various diagnostic criteria have been proposed. Bocquet et al stipulated the presence of (1) cutaneous drug eruption; (2) hematologic abnormalities including eosinophilia greater than $1.5 \times 10^{9} / \mathrm{L}$ or the presence of atypical lymphocytes; and (3) systemic involvement including adenopathy greater than $2 \mathrm{~cm}$ in diameter, hepatitis (liver transaminase values $>2$ normal), interstitial nephritis, interstitial pneumonia, or carditis.

Kardaun et al developed a scoring system to validate the diagnosis [187].

The potential role of HHV-6 in the pathogenesis of DIHS was incorporated into the criteria for DIHS by the JSCAR group [188]: (1) maculopapular rash developing more than 3 weeks after starting a limited number of drugs; (2) prolonged clinical symptoms 2 weeks after discontinuation of the causative drug; (3) fever greater than 38 C; (4) liver abnormalities (eg, ALT levels $>100 \mathrm{U} / \mathrm{L})$; (5) leukocyte abnormalities such as leukocytosis ( $\left.>11 \times 10^{9} / \mathrm{L}\right)$, atypical lymphocytosis (>5\%), and/or eosinophilia (>1.5 109/L); (6) lymphadenopathy; and (7) HHV-6 reactivation. Diagnosis of typical DIHS requires the presence of all 7 criteria. If criteria 1-5 are present only, then a diagnosis of atypical DIHS is made.

The syndrome typically begins 3 weeks to 3 months after commencing therapy with a limited number of drugs of which the most prominent ones are listed below. 


\begin{tabular}{|c|c|c|c|c|c|c|}
\hline Assessment/Score & -1 & 0 & 1 & 2 & $\min$ & $\max$ \\
\hline Fever $\geq 38.5^{\circ} \mathrm{C}$ & $\mathrm{n}$ & y & & & -1 & 0 \\
\hline Enlarged lymph nodes & & $\mathrm{n} / \mathrm{u}$ & y & & 0 & 1 \\
\hline \multicolumn{7}{|l|}{ Eosinophilia } \\
\hline Eosinophilia & & $\mathrm{n} / \mathrm{u}$ & $700-1499 / \mu \mathrm{L}$ & $" />1500 / \mu \mathrm{L}$ & 0 & 2 \\
\hline Eosinophilia if WCC $<4000 / \mu \mathrm{L}$ & & & $10-19.9 \%$ & $\geq 20 \%$ & & \\
\hline Atyical lymphocytes & & $\mathrm{n} / \mathrm{u}$ & $\mathrm{y}$ & & 0 & 1 \\
\hline \multicolumn{7}{|l|}{ Skin involvement } \\
\hline Skin rash extent (\%TBSA) & & $\mathrm{n} / \mathrm{u}$ & $" />50 \%$ & & & \\
\hline Skin rash suggestive of DRESS & $\mathrm{n}$ & u & y & & -2 & 2 \\
\hline Histology suggestive of DRESS & $\mathrm{n}$ & $y / u$ & & & & \\
\hline \multicolumn{7}{|l|}{ Organ involvement * } \\
\hline \multicolumn{7}{|l|}{ Liver } \\
\hline \multicolumn{7}{|l|}{ Kidney } \\
\hline Lung & & $\mathrm{n} / \mathrm{u}$ & $" />1$ y & $\geq 2 y$ & 0 & 2 \\
\hline
\end{tabular}

\section{Pancreas}

Other organ

\begin{tabular}{|c|c|c|c|c|}
\hline Resolution $\geq 15$ days & $n \quad y$ & & -1 & 0 \\
\hline \multicolumn{5}{|l|}{ Serology/PCR } \\
\hline \multicolumn{5}{|l|}{ Hepatitis A,B,C } \\
\hline \multicolumn{5}{|l|}{ EBV,CMV } \\
\hline \multicolumn{5}{|l|}{ Mycoplasma,Chlamydia } \\
\hline \multicolumn{5}{|l|}{ ANA } \\
\hline \multicolumn{5}{|l|}{ Blood culture } \\
\hline If non +ve and $\geq 3$-ve & & $n$ & 0 & 1 \\
\hline Total & & & -4 & 9 \\
\hline
\end{tabular}

$y$, yes; $n$, no.

*After exclusion of other causes: 0 , no organ involvement; 1,1 organ involved; 2, 22 organs involved.

Final score: $<2$, excluded; $2-3$, possible; $4-5$, probable; $>5$, definite.

Table 3. Diagnostic validation score for DRESS

High-grade fever $\left(38-40^{\circ} \mathrm{C}\right)$ is usually the first symptom followed by the development of facial oedema (Fig. 8), often with pinhead-sized pustules, and an erythroderma with edematous, follicular and purpuric lesions (Fig. 9). An exfoliative dermatitis often eventuates especially if 
Carbamazepine

Phenytoin

Phenobarbitol

Zonisamide

Lamotrigine

Allopurinol

Dapsone

Sulphasalazine

Mexiletine

Minocycline

Strontium ranelate

Abacavir

Table 4. The main causative drugs of DIHS

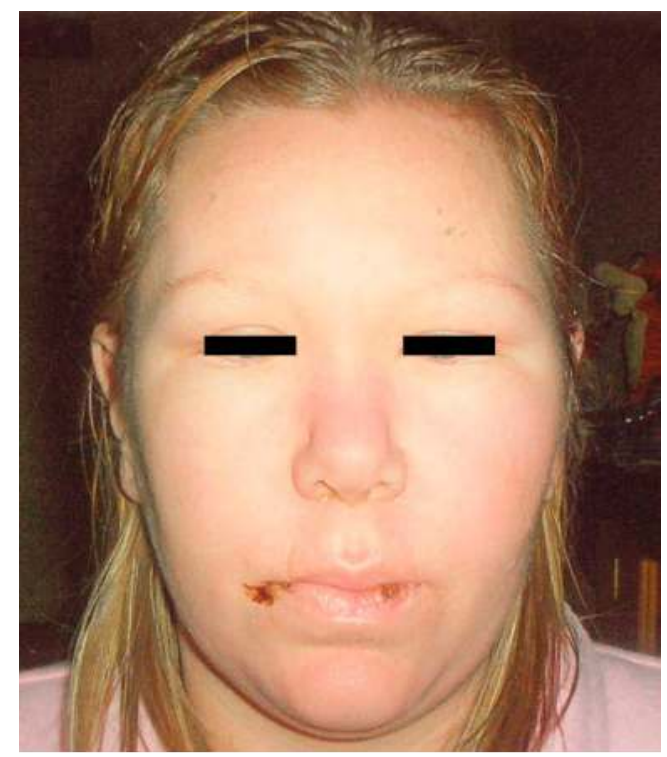

Figure 8. Facial erythema and edema with labial ulceration in a young woman with DIHS/DRESS. 
the causative drug is not withdrawn (Fig. 10). Cheilitis (Fig. 8), pharyngeal erythema and oral ulceration may occur but severe stomatitis is not present. Tender lymphadenopathy in more than two sites and bilateral swelling of salivary glands with xerostomia is evident early in the course of disease. Hepatosplenomegaly is a common finding. Leukocytosis with atypical lymphocytes and eosinophilia (60-70\% of cases) is a prominent feature of this syndrome although the eosinophilia may not be observed for 1-2 weeks. Thrombocytopenia and anemia may also be present. Hypogammaglobulinema is noted at the onset of disease with the nadir occurring several days after the withdrawal of the causative drug [189]. An overshoot in the IgG level occurs 1-2 weeks after the nadir before returning to normal on full recovery. Internal organ involvement is listed in table 5 .

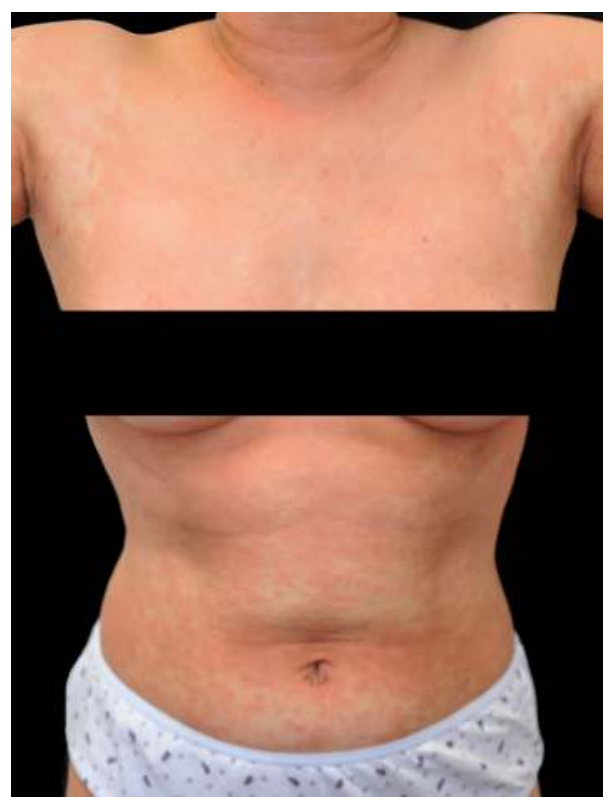

Figure 9. Maculopapular eruption and erythroderma of the trunk in DIHS.

The onset of symptoms is variable with patients developing 2-3 symptomatic features followed by stepwise development of other manifestations. In most cases, withdrawal of the drug is not followed by rapid resolution of symptoms. Many patients may continue to deteriorate and show periodic relapses for weeks after the withdrawal of the causative drug.

Several reports have described the occurrence of autoantibody formation and autoimmune diseases up to 4 years after the acute resolution of DIHS/DRESS [201] and these include type 1 diabetes mellitus [202], autoimmune thyroid disease [203], scleroderma GVHD [204], SLE [205], and bullous pemphigoid [206]. One of the likely explanations for the occurrence of autoimmune disease is the depletion of regulatory $\mathrm{T}$ cells upon recovery of disease. 


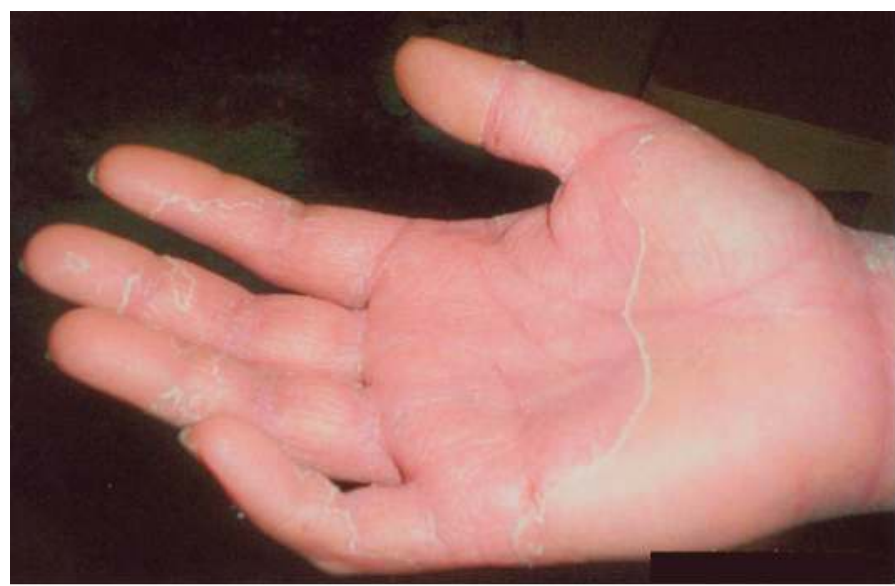

Figure 10. Exfoliative dermatitis involving the hand in a young woman with DIHS/DRESS who had continued to ingest the culprit drug for 4 weeks when this image was taken.

\begin{tabular}{|c|c|}
\hline Manifestation & Comments \\
\hline Hepatitis (mixed hepatocellular and cholestatic) & $71 \%{ }^{[190]}$ \\
\hline Interstitial nephritis & $\begin{array}{l}11 \% \text {, frequent with Allopurinol-induced } \\
\text { DIHS }^{[191]}\end{array}$ \\
\hline Pneumonitis/pleuritis & $\begin{array}{l}\text { Common in minocycline }{ }^{[192]} \text { and abacavir }{ }^{[193]} \\
\text { induced DIHS }\end{array}$ \\
\hline Myocarditis & $\begin{array}{l}\text { Occurs at onset or } 40 \text { days after onset of } \\
\text { DIHS }\end{array}$ \\
\hline Limbic encephalitis & $\begin{array}{l}\text { 2-4 weeks after onset of DIHS, HHV-6 } \\
\text { reactivation in } \text { CSF }^{[195]} \\
\text { May be assoiciated with SiADH }{ }^{[196]}\end{array}$ \\
\hline CMV Gastrointestinal ulceration with bleeding & 4-5 weeks after onset of DIHS ${ }^{[197]}$ \\
\hline Haemaophagocytic syndrome & Rare, occurs 2 weeks after onset of disease ${ }^{[198]}$ \\
\hline Parotid gland enlargement & Rare $^{[199]}$ \\
\hline Pancreatitis & Rare $^{[200]}$ \\
\hline
\end{tabular}

Table 5. Internal organ involvement in DIHS

Abacavir, an HIV nucleoside analogue reverse transcriptase inhibitor causes a potentially lifethreatening hypersensitivity syndrome in approximately 5-8\% of recipients within 6 weeks of therapy [207],[208]. The clinical and laboratory features of this syndrome differs from typical cases of DIHS/DRESS in that there is a predilection for the gastrointestinal system with nausea, abdominal pain, diarrhoea, and the respiratory tract with cough, pharyngitis and shortness of 
breath. Headache, myalgia and/or arthralgia may also be present. Eosinophilia is present in < $10 \%$ of cases and liver function test abnormalities are detected in $<20 \%$ of cases [209]. Also, the manifestations resolve within 72 hours rather than having a protracted relapsing course and the role of herpetic viruses in this condition is unknown.

\subsection{Differential diagnosis}

Viral infections such as EBV, CMV, and measles can be distinguished by the absence of eosinophilia, hypogammaglobulinemia, and supportive serology. In children, DIHS/DRESS is differentiated from Kawasaki's disease by the absence of a bulbar conjunctivitis, strawberry tongue, coronary aneurysms, hypoalbuminemia and thrombocytosis. Serum sickness is characterized by urticarial lesions and the absence of internal organ involvement. Atopic erythroderma with bacterial infection does not usually involve hepatitis or nephritis. Druginduced pseudolymphoma from carbamazepine or phenytoin is distinguished from DIHS/ DRESS by the absence of internal organ involvement and the prompt resolution of symptoms when the drug is withdrawn. Cutaneous $\mathrm{B}$ and $\mathrm{T}$ cell lymphomas have an indolent course and characteristic histopathology.

\subsection{Pathology}

The histopathology of DIHS/DRESS is relatively non-specific and consists of a lymphocytic infiltrate that is superficial, perivascular, dense and diffuse. Eosinophils may be present but is often absent. The presence of loose rather than discrete granulomatous aggregates of histiocytes have been recently reported (Figs. 11, 12) [210]. This may be due to continued exposure to the culprit drug after the onset of DIHS/DRESS. Granuloma formation occurs as a consequence of a delayed-type hypersensitivity (type IV) reaction, the classic example of which is the tuberculin reaction where a cutaneous granuloma is induced after injection of purified protein derivative in a previously sensitized individual. The expansion of CD4 cells and the secretion of IFN- $\gamma$ and other Th- 1 cytokines result in the recruitment of macrophages. Sustained drug exposure and the persistence of cytokine release promote differentiation of macrophages into epithelioid cells, which secrete TNF promoting their fusion to form multinucleate giant cells and granulomas. HHV-6 and DNA from other herpes viruses may be detected in skin lesions by PCR or in situ hybridization [183].

\subsection{Drug allergy testing}

\subsubsection{Patch tests}

Santiago et al recently studied the utility of patch testing in DIHS/DRESS and found a positive reaction in $32 \%$ of the 56 patients. Patch testing was performed between 6 weeks and 6 months after healing of the lesion and at least one month after corticosteroids were ceased. They found that $76 \%$ of the 17 patients with carbamazepine-induced DIHS/DRESS were patch test positive but none of the 19 allopurinol-sensitive patients were positive to allopurinol and its metabolite, oxypurinol. No systemic reactions occurred during or after testing [211]. Hence patch testing may prove useful once the reagent and timing of such testing is optimized. Patch testing has, 


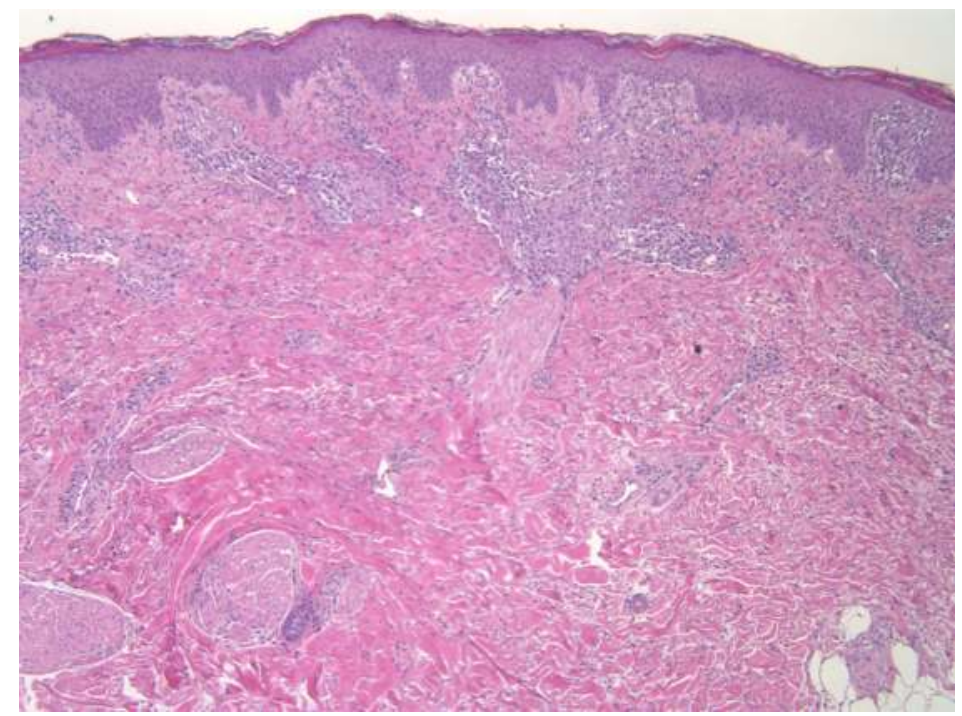

Figure 11. Low power view of a skin biopsy from a patient with DIHS demonstrating the superficial dermal nature and perivascular distribution of the inflammatory infiltrate with acanthosis and hyperkeratosis of the epidermis (Hematoxylin-eosin, original magnification $\times 40$ ).

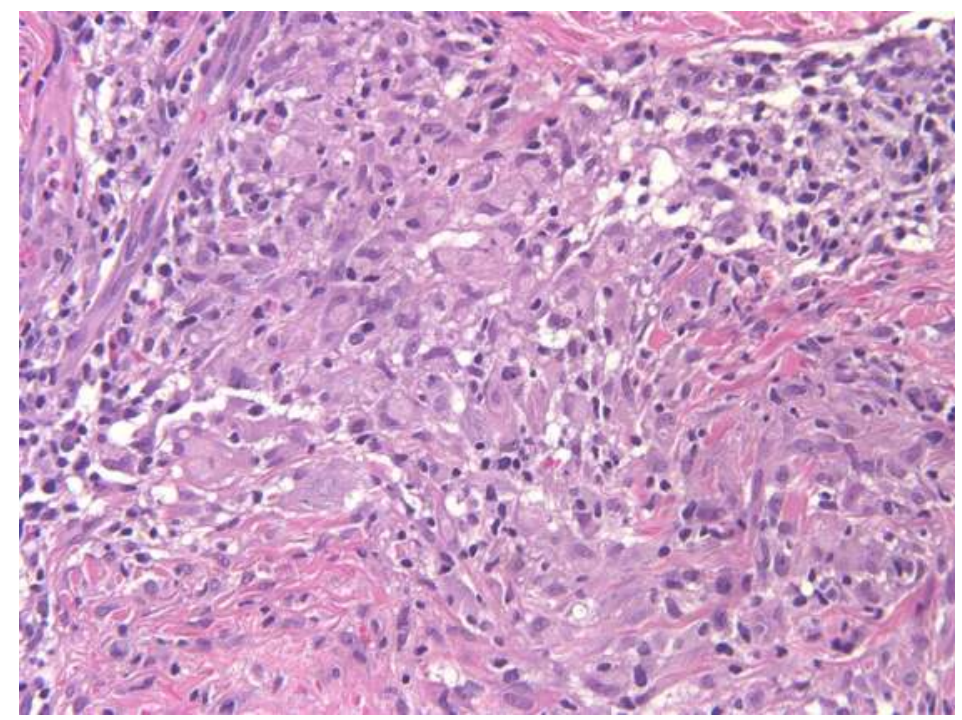

Figure 12. High power view of a skin biopsy from a patient with DIHS demonstrates granulomatous inflammation with prominent, but relatively loosely aggregated histiocytes, mixed with lymphocytes. Eosinophils are absent (Hematoxylin-eosin, original magnification $\times 200$ ). 
however, proven to be very useful in confirming suspected cases for abacavir hypersensitivity with a higher degree of specificity than can be confirmed clinically [212].

\subsubsection{Lymphocyte transformation tests(LTTs)}

LTTs are usually negative up to 3 weeks after the onset of DIHS/DRESS but most patients are positive at 5-7 weeks and have persistent responses even at 1 year. Treatment with corticosteroids did not affect the results [97]. One possible explanation for the negative LTT result during the acute phase of DIHS is the expansion T regulatory cells with a naïve phenotype (CD4CD25FoxP3), which then are depleted by apoptosis during the recovery phase. These regulatory T cells are capable of suppressing proliferation of memory T cells in LTTs [55].

\subsection{Pathogenesis}

The pathogenesis of DIHS/DRESS is still to be fully elucidated. The precise role of HHV-6 in DIHS is unclear. The initiating event may be the reactivation of one or more herpetic viruses, which is clinically unapparent. Virus-stimulated T cells may then cross react with drug-derived hapten-protein conjugates that are presented by dendritic cells to naïve antigen-specific CD4 T-cells with the subsequent differentiation into effector/memory CD4 cells. These dendritic cells may also activate CD8 T-cells by cross-presentation. The expansion of effector CD4 T-cells with their production of IFN- $\gamma$ and other cytokines results in recruitment and activation of macrophages. Failure to eradicate the antigenic stimulus, in this instance due to the continued ingestion of the drug, causes persistent cytokine release and promotes differentiation of macrophages into epithelioid cells, which secrete large amounts of TNF promoting their fusion to form multinucleate giant cells [210]. Analogous to that observed in GVHD, longitudinal real-time PCR analyses of viral loads in blood samples drawn from patients with DIHS show that various herpetic viruses are sequentially activated as a result of massive $T$ cell stimulation, B cell loss and hypogammaglobulinemia [213]; Activation of Epstein-Barr virus or HHV-6 extends to the sequential activation of HHV-7, cytomegalovirus and varicella-zoster virus [189]. The frequent deterioration or several exacerbations that occur despite continuation of the drug may at least be partly explained by sequential reactivation of herpetic viruses and the immune response to viral replication. An alternative explanation is that drug specific $T$ cells are activated resulting in reactivation of the viral genome and sequential reactivation of herpes viruses.

Genetic susceptibility may also play a role as all patients with allopurinol-induced DIHS in a Han Chinese population harboured the $H L A-B^{*} 5801$ allele compared with $15 \%$ of control subjects [67]. Recently, an association was described between HLA-A*3101 and DIHS in Northern Europeans; OR 12.41 [1.27-121.03] [64] and in the Japanese; OR 9.5 [4.6-19.5] [65]. In a Western Australian HIV Cohort Study, HLA-B*5701 was present in $14(78 \%)$ of the 18 patients with abacavir hypersensitivity, and in four (2\%) of the 167 abacavir tolerant patients; OR 117 [29-481] [193]. There is a discrepancy in the association of $H L A-B^{*} 5701$ and abacavir hypersensitivity across various racial groups The association was confirmed in a separate cohort of HIV-infected white Americans and was also found to confer susceptibility in Hispanics but not in blacks [214]. No association was found in a cohort of Korean patients [215]. Hence 
screening for $H L A-B^{*} 5701$ is not useful in predicting sensitivity in all patients. The racial variation may be partly explained by the differences in MHC haplotypes across different racial groups. The Caucasian 57.1 ancestral haplotype, which confers susceptibility to abacavir hypersensitivity possibly as a result of strong linkage disequilibrium with other candidate genetic factors such as cellular chaperones (e.g. heat shock proteins), inflammatory cytokines (e.g. TNF), and proteins involved in the stress response (e.g. MHC class I chain-related genes, MIC-A and MIC-B). African populations do not demonstrate this haplotype [216]. However, in a recent study by Saag et al, all 42 white patients with immunologically confirmed (i.e. positive patch tests) hypersensitivity reactions were $H L A-B * 5701$ positive (sensitivity $100 \%$, OR 1945 [110-34,352]) but in addition all 5 black patients with immunologically confirmed hypersensitivity reactions were $H L A-B^{*} 5701$ positive (sensitivity $100 \%$, OR 900 [ 38-21,045]. Screening for the $H L A-B^{*} 5701$ has eliminated immunologically confirmed cases of abacavir hypersensitivity [217].

\subsection{Treatment}

Early recognition of the syndrome with cessation of the causative drug is essential in improving patient outcomes. No randomized controlled trials have been conducted to determine the appropriate adjunctive therapy for DIHS/DRESS. Oral corticosteroids at $1 \mathrm{mg} / \mathrm{kg} / \mathrm{daily}$ is commenced and tapered over at least 6-8 weeks to prevent relapse of various cutaneous and visceral manifestations of the syndrome. If symptoms deteriorate despite corticosteroid therapy then IVIg [218],[219], plasma exchange [220], rituximab, gangciclovir or a combination of these modalities [221] can be considered.

Recently, the French Society of Dermatology formulated guidelines on the management of DIHS/DRESS [133]:

1. Absence of signs of severity: topical corticosteroids, emollients and H1-antihistamines.

2. Presence of signs of severity (transaminases $>5$ times normal, renal impairment, pneumonia, hemophagocytosis, cardiac involvement): prednisone $1 \mathrm{mg} / \mathrm{kg} / \mathrm{day}$.

3. Life-threatening signs: (hemophagocytosis with bone marrow failure, encephalitis, severe hepatitis, renal failure, respiratory failure): prednisone and IVIg $2 \mathrm{~g} / \mathrm{kg}$ over 5 days.

4. Presence of signs of severity with confirmation of major viral reactivation: prednisone and gangciclovir and/or IVIg.

\section{Acute generalized exanthematous pustulosis}

\subsection{Nosology}

In 1980, Beylot et al [222] introduced the term acute generalized exanthematous pustulosis (AGEP) to describe acute pustular reactions with distinct clinical and histological features thereby differentiating it from pustular psoriasis. 


\subsection{Epidemiology}

AGEP is rare with an incidence of 1-5 cases per million per year [223]. The EuroSCAR study comprising 97 validated cases of AGEP recruited from Austria, France, Israel, Italy and the Netherlands, revealed a mean age $( \pm S D)$ of $56( \pm 21)$ years and a female preponderance with a male/female ratio of 0.8 [18]. The predominance in women was shown to be even greater in case series reports from Taiwan (68.7\% of 16 cases) [224], and Israel (76.9\% of 13 cases) [225]. AGEP has been reported in children, with the largest pediatric series of 20 cases from China [226].

\subsection{Clinical features}

The clinical manifestations are characterized by fever and a pruritic or burning edematous erythema (Figs. $13 \mathrm{~A} \& \mathrm{~B})$ followed by the rapid appearance of dozens of small $(<5 \mathrm{~mm})$ nonfollicular sterile pustules (Fig. 14). The skin lesions are often accentuated in the intertriginous areas (Fig. $13 \mathrm{C}$ ). There is usually an accompanying marked neutrophilia $\left(7 \times 10^{9} / \mathrm{L}\right)$ and in a third of cases, a mild eosinophilia. A mild non-erosive mucous membrane involvement occurs in $20 \%$ of cases. Internal organ involvement is uncommon and usually is confined to a slight reduction in creatinine clearance and mild elevation of aminotransferases.

The clinical course is characterized by spontaneous resolution of skin and systemic manifestations over a period of up to 15 days once the offending agent is withdrawn [223]. AGEP has a favourable prognosis; the reported mortality rate is up to $5 \%$ and poor outcomes usually result from secondary infection in the elderly or those patients with significant comorbidities [227],[228].

\subsection{Etiology}

AGEP is caused by drugs in at least $90 \%$ of cases. According to the EuroSCAR study, the agents conferring the highest risk are pristinamycin, aminopenicillins, hydroxychloroquine, antibacterial sulphonamides, terbinafine and diltiazem [18]. The latent period is short (usually 1-5 days) with the EuroScar study demonstrating that it may vary for different drugs. For antibiotics, including sulphonamides, the median latent period was 1 day, and for other drugs it was 11 days [18].

Contact sensitivity has been implicated in a few case reports. Causative agents include mercury[229], and bufexemac, a potent topical NSAID[230]. Neither of these agents was implicated in the 97 cases of AGEP in the EuroScar. The role of infectious agents in AGEP has been suggested in various case reports due to the absence of an inciting drug [231]. The organisms include coxsackie B4 [232], cytomegalovirus [233], parvovirus B19 [234], Chlamydia pneumoniae [235], and Escherichia coli [236]. No significant risk for infection was found in the EuroScar study although the study was not designed to identify potential causative organisms. Spider bites were suggested as a cause AGEP in a series of three cases from Israel, presumably as a result of the venom's ability to induce IL-8 and GM-CSF [237]. Finally, as illustrated in two recent cases, AGEP may develop without preceding medication or disease [238]. 


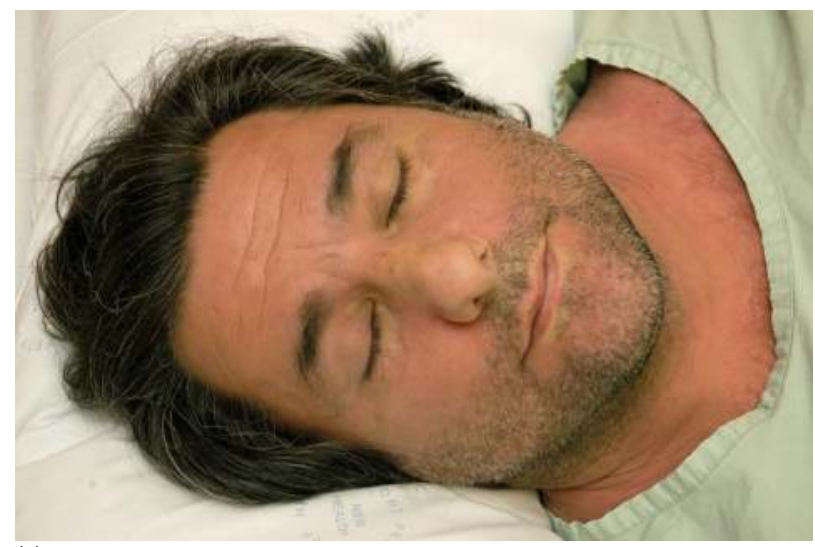

(a)

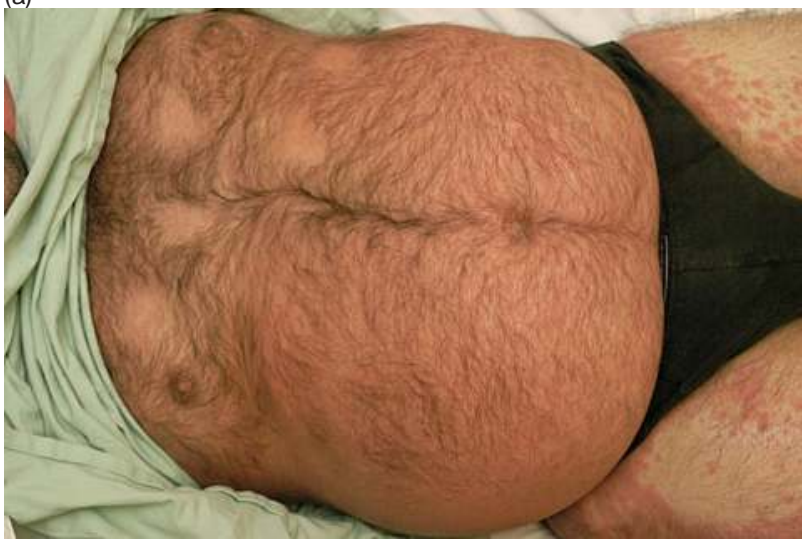

(b)

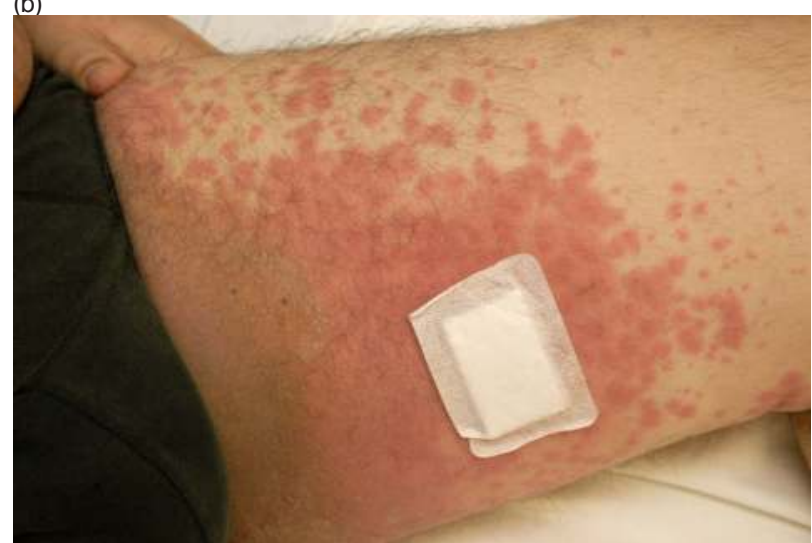

(c)

Figure 13. This patient with AGEP had an onset of erythema and edema of the face (A), erythema of the trunk (B) with a predilection for intertriginous areas (C). 


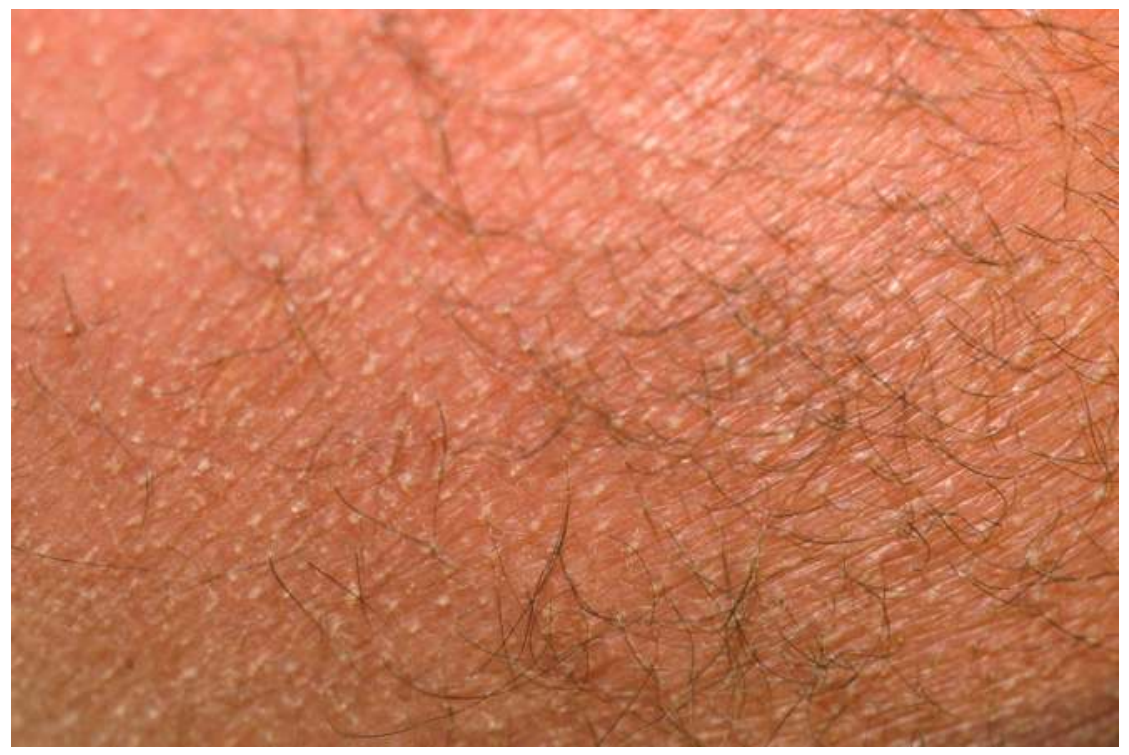

Figure 14. The lesions of AGEP occur rapidly and are characterized by dozens of small ( $<5 \mathrm{~mm}$ ) non-follicular sterile pustules.

\subsection{Pathogenesis}

The pathogenesis of AGEP has been elucidated by patch [239],[240] and in vitro tests [241][243] and initially involves activation, expansion and subsequent migration of drug-specific CD4 and CD8 cells to the skin. The initial influx of CD8 cytotoxic T cells results in apoptosis of keratinocytes and the formation of subcorneal vesicles. The infiltrating CD4 cells release CXCL-8, which results in recruitment of neutrophils, and granulocyte macrophage-colony stimulating factor (GM-CSF), which prevents apoptosis of neutrophils. This results in the conversion of vesicles into pustules. CD4 cells also release IFN- $\gamma$, which stimulates keratinocytes to secrete CXCL-8, as well as RANTES and IL-5, which contributes to the eosinophilia observed in some patients [244]. Resident Langerhans' cells may present drug antigens to CD4 cells and keratinocytes may act as antigen presenting cells to CD8 cells thereby augmenting the neutrophil-mediated inflammatory response. Genetic susceptibility to AGEP has not been robustly examined and therefore remains largely unknown.

\subsection{Diagnostic tests}

A pustular smear should be performed to exclude an infectious aetiology. A full blood count will reveal a neutrophilia. A skin biopsy may show (spongiform or non-spongiform) subcorneal and/or intradermal pustules, edema of the papillary dermis, perivascular infiltrates with neutrophils and exocytosis of some eosinophils and focal necrotic keratinocytes (Fig. 15). The typical changes of psoriasis such as acanthosis and papillomatosis are usually absent. Patch testing may be useful in confirming the association between AGEP and the culprit drugs. In a 
controlled study, patch tests were positive in half of the 14 cases of AGEP [96]. Readings should not be restricted to 24 and 48 hours after the application of the drug but should also be determined at 96 and 120 hours to maximise sensitivity. Pustule formation is often observed in positive patch tests in cases of AGEP. The test can be conducted one month after resolution of the disease. The risk of AGEP with patch testing is considered to be low but not negligible [245]. A small number of studies have supported a role for LTT [246], IFN- $\gamma$ release [247], lymphokine macrophage migration inhibition factor release assays [241] but these in vitro tests are not widely available and its value remains to be determined in large cohorts.

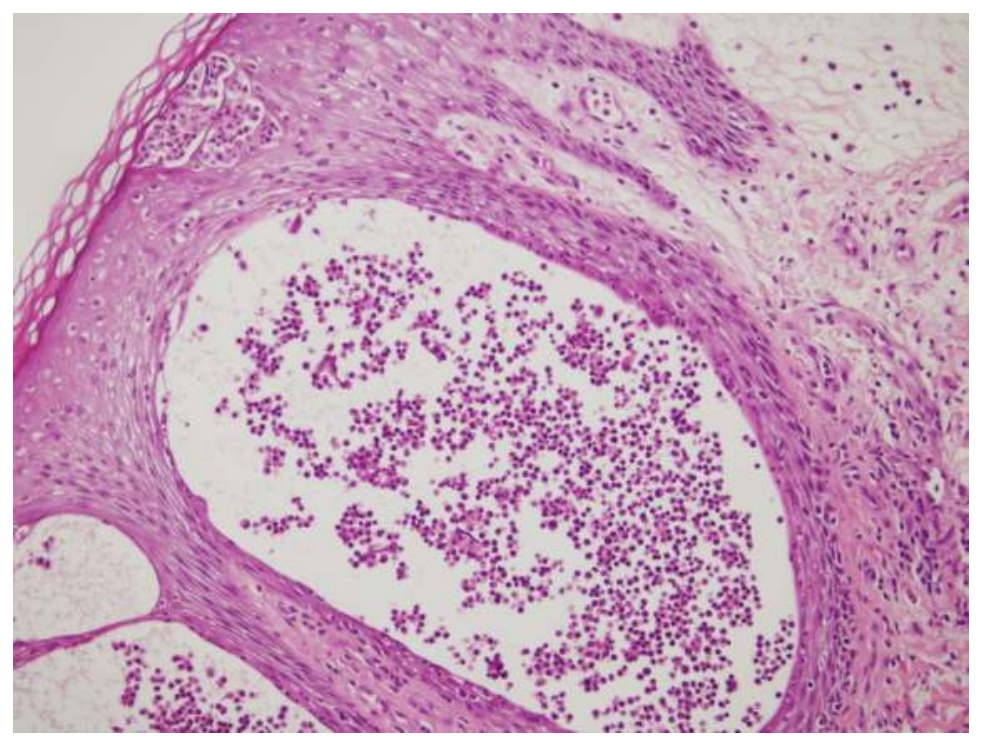

Figure 15. A moderate power view of a skin biopsy from a patient with AGEP shows spongiform subcorneal pustules, edema of the papillary dermis and perivascular infiltrates with neutrophils and exocytosis of some eosinophils.

\begin{tabular}{ll}
\hline $\begin{array}{l}\text { Morphology } \\
\text { Pustules }\end{array}$ & +2 \\
\hline Typical & +1 \\
\hline Compatible with disease & 0 \\
\hline Insufficient & +2 \\
\hline Erythema & +1 \\
\hline Typical & 0 \\
\hline Compatible with disease & \\
\hline Insufficient &
\end{tabular}




\section{Morphology}

\section{Pustules}

\begin{tabular}{ll}
\hline Typical & +2 \\
\hline Compatible with disease & +1 \\
\hline Insufficient & 0 \\
\hline Post pustular desquamation & +1 \\
\hline Yes & 0 \\
\hline No & \\
\hline Course & -2 \\
\hline Mucous membrane involvement & 0 \\
\hline Yes & \\
\hline No & 0 \\
\hline Acute onset & -2 \\
\hline Yes & 0 \\
\hline No & -4 \\
\hline Resolution & +1 \\
\hline Yes & 0 \\
\hline No & \\
\hline Fever $\geq 38^{\circ} \mathrm{C}$ & \\
\hline Nes & \\
\hline No & \\
\hline
\end{tabular}

Polymorphonuclear cells $\geq 7 / \mu 1$

\begin{tabular}{ll}
\hline Yes & +1 \\
\hline No & 0
\end{tabular}

Histology

\begin{tabular}{ll}
\hline Other disease & -10 \\
\hline Not representative & 0 \\
\hline Exocytosis of polymorphonuclear cells & +1
\end{tabular}

Subcorneal and/or intraepidermal non-spongiform pustules or +2 NOS pustules with papillary edema or subcorneal and/or intraepidermal spongiform pustulea or NOS pustules without papillary edema

Spongiform subcorneal and/or intraepidermal pustules with +3 papillary edema

NOS, not otherwise specified.

Score $\leq$ 0; excluded, 1-4: possible, 5-7: probable, 8-12: definite

Table 6. Diagnostic score for validation of AGEP 


\subsection{Differential diagnosis}

AGEP, which is characterized by non-follicular pustules can be readily distinguished from diseases with follicular pustulosis such as bacterial folliculitis, furunculosis, acneiform eruptions, pustular contact dermatitis, dermatophyte infection, viral exanthema with primary vesiculation and secondary postulation, impetigo, Sweet syndrome and SSSS. Other diseases are not as easily differentiated from AGEP. Generalized pustular psoriasis (Zumbusch psoriasis) is characterized by pustules that slowly develop on areas of psoriasis accompanied by the histological changes of psoriasis on skin biopsy. There is also usually a family history of psoriasis. Sneddon-Wilkinson disease (subcorneal pustulosis) and subcorneal IgA dermatosis are characterized by the subacute development of larger pustules than those that erupt in AGEP and maybe associated with hyopyon formation.

A diagnostic score was devised to validate the diagnosis of AGEP based on the morphology, course of disease, and histology and assist in the differentiation from similar diseases [223].

\subsection{Treatment}

As AGEP is a self-limiting disease with a favourable prognosis. Cessation of the causative agent and supportive treatment is usually all that his required. In the pustular phase, supportive measures consist of moist dressings with drying and disinfecting solutions to avoid superinfection. In the postpustular desquamation phase, emollients are used to optimise preservation of skin barrier function. In a study of nine cases from Israel, all of who made a full recovery, seven received supportive care alone and the other two received corticosteroids [248]. It remains to be established whether oral or parenteral corticosteroids hasten the resolution of disease. A brief course of systemic corticosteroids may be considered in patients with severe and widespread inflammation of the skin.

\section{Conclusion}

SCARs such as SJS/TEN, DIHS/DRESS, and AGEP are idiosyncratic and specific types of reactions that have distinct clinical, laboratory and histological features. The definition of DIHS/DRESS has not been universally adopted and will need to be clarified once the role of herpetic viruses and characteristic histological features are known. The early identification of these reactions and the subsequent prompt withdrawal of therapy and the implementation of supportive and adjunctive therapies are crucial in minimising morbidity and rates of mortality. Multicentre randomized studies are required to adopt the most suitable therapies for these potentially life-threatening conditions. The emergence in the understanding of HLA susceptibility genes will enable patients to be screened for the risk of developing a SCAR and will hopefully be more widely performed once cost effective and rapid methods of detection are widely available to the prescribing doctor. 


\title{
Author details
}

\author{
Suran L. Fernando ${ }^{1,2}$
}

1 Department of Clinical Immunology and Allergy, Royal North Shore Hospital, Sydney, Australia

2 Sydney Medical School - Northern, Sydney University, Sydney, Australia

\section{References}

[1] von Hebra F. Acute exantheme und hautkrankheiten. Handbuch der Speciellen Pathologie und Therapie 1860:198-200.

[2] Stevens AM, Johnson FC. A new eruptive fever associated with stomatitis and ophthalmia: report of two cases in children. Am J Dis Child 1922;24:526-533.

[3] Thomas BA. The so-called Stevens-Johnson syndrome. Br Med J 1950;1(4667):1393-7.

[4] Lyell A. Toxic epidermal necrolysis: an eruption resembling scalding of the skin. $\mathrm{Br}$ J Dermatol 1956;68(11):355-61.

[5] Ruiz-Maldonado R. Acute disseminated epidermal necrosis types 1, 2, and 3: study of sixty cases. J Am Acad Dermatol 1985;13(4):623-35.

[6] Lyell A. Requiem for toxic epidermal necrolysis. Br J Dermatol 1990;122(6):837-8.

[7] Bastuji-Garin S, Rzany B, Stern RS, Shear NH, Naldi L, Roujeau JC. Clinical classification of cases of toxic epidermal necrolysis, Stevens-Johnson syndrome, and erythema multiforme. Arch Dermatol 1993;129(1):92-6.

[8] Kokuba H, Imafuku S, Huang S, Aurelian L, Burnett JW. Erythema multiforme lesions are associated with expression of a herpes simplex virus (HSV) gene and qualitative alterations in the HSV-specific T-cell response. Br J Dermatol 1998;138(6):952-64.

[9] Villiger RM, von Vigier RO, Ramelli GP, Hassink RI, Bianchetti MG. Precipitants in 42 cases of erythema multiforme. Eur J Pediatr 1999;158(11):929-32.

[10] Ng PP, Sun YJ, Tan HH, Tan SH. Detection of herpes simplex virus genomic DNA in various subsets of Erythema multiforme by polymerase chain reaction. Dermatology 2003;207(4):349-53.

[11] Mockenhaupt M, Viboud C, Dunant A, et al. Stevens-Johnson syndrome and toxic epidermal necrolysis: assessment of medication risks with emphasis on recently marketed drugs. The EuroSCAR-study. J Invest Dermatol 2008;128(1):35-44. 
[12] Carrozzo M, Togliatto M, Gandolfo S. [Erythema multiforme. A heterogeneous pathologic phenotype]. Minerva Stomatol 1999;48(5):217-26.

[13] Lam NS, Yang YH, Wang LC, Lin YT, Chiang BL. Clinical characteristics of childhood erythema multiforme, Stevens-Johnson syndrome and toxic epidermal necrolysis in Taiwanese children. J Microbiol Immunol Infect 2004;37(6):366-70.

[14] Cote B, Wechsler J, Bastuji-Garin S, Assier H, Revuz J, Roujeau JC. Clinicopathologic correlation in erythema multiforme and Stevens-Johnson syndrome. Arch Dermatol 1995;131(11):1268-72.

[15] Rzany B, Mockenhaupt M, Baur S, et al. Epidemiology of erythema exsudativum multiforme majus, Stevens-Johnson syndrome, and toxic epidermal necrolysis in Germany (1990-1992): structure and results of a population-based registry. J Clin Epidemiol 1996;49(7):769-73.

[16] Kelly JP, Auquier A, Rzany B, et al. An international collaborative case-control study of severe cutaneous adverse reactions (SCAR). Design and methods. J Clin Epidemiol 1995;48(9):1099-108.

[17] Roujeau JC, Kelly JP, Naldi L, et al. Medication use and the risk of Stevens-Johnson syndrome or toxic epidermal necrolysis. N Engl J Med 1995;333(24):1600-7.

[18] Sidoroff A, Dunant A, Viboud C, et al. Risk factors for acute generalized exanthematous pustulosis (AGEP)-results of a multinational case-control study (EuroSCAR). $\mathrm{Br}$ J Dermatol 2007;157(5):989-96.

[19] Rzany B, Correia O, Kelly JP, Naldi L, Auquier A, Stern R. Risk of Stevens-Johnson syndrome and toxic epidermal necrolysis during first weeks of antiepileptic therapy: a case-control study. Study Group of the International Case Control Study on Severe Cutaneous Adverse Reactions. Lancet 1999;353(9171):2190-4.

[20] Levi N, Bastuji-Garin S, Mockenhaupt M, et al. Medications as risk factors of StevensJohnson syndrome and toxic epidermal necrolysis in children: a pooled analysis. $P e^{-}$ diatrics 2009;123(2):e297-304.

[21] Fournier S, Bastuji-Garin S, Mentec H, Revuz J, Roujeau JC. Toxic epidermal necrolysis associated with Mycoplasma pneumoniae infection. Eur J Clin Microbiol Infect Dis 1995;14(6):558-9.

[22] Ball R, Ball LK, Wise RP, Braun MM, Beeler JA, Salive ME. Stevens-Johnson syndrome and toxic epidermal necrolysis after vaccination: reports to the vaccine adverse event reporting system. Pediatr Infect Dis J 2001;20(2):219-23.

[23] House RA, Jakubovic H, Wong L, Holness DL. Work-related toxic epidermal necrolysis? J Occup Med 1992;34(2):135-9.

[24] Revuz J, Roujeau JC, Guillaume JC, Penso D, Touraine R. Treatment of toxic epidermal necrolysis. Creteil's experience. Arch Dermatol 1987;123(9):1156-8. 
[25] Letko E, Papaliodis DN, Papaliodis GN, Daoud YJ, Ahmed AR, Foster CS. StevensJohnson syndrome and toxic epidermal necrolysis: a review of the literature. Ann Allergy Asthma Immunol 2005;94(4):419-36; quiz 436-8, 456.

[26] Lebargy F, Wolkenstein P, Gisselbrecht M, et al. Pulmonary complications in toxic epidermal necrolysis: a prospective clinical study. Intensive Care Med 1997;23(12): 1237-44.

[27] Kim MJ, Lee KY. Bronchiolitis obliterans in children with Stevens-Johnson syndrome: follow-up with high resolution CT. Pediatr Radiol 1996;26(1):22-5.

[28] Sugimoto Y, Mizutani H, Sato T, Kawamura N, Ohkouchi K, Shimizu M. Toxic epidermal necrolysis with severe gastrointestinal mucosal cell death: a patient who excreted long tubes of dead intestinal epithelium. J Dermatol 1998;25(8):533-8.

[29] Atiyeh BS, Dham R, Yassin MF, El-Musa KA. Treatment of toxic epidermal necrolysis with moisture-retentive ointment: a case report and review of the literature. Dermatol Surg 2003;29(2):185-8.

[30] Wolkenstein P, Revuz J. Toxic epidermal necrolysis. Dermatol Clin 2000;18(3):485-95, ix.

[31] Abood GJ, Nickoloff BJ, Gamelli RL. Treatment strategies in toxic epidermal necrolysis syndrome: where are we at? J Burn Care Res 2008;29(1):269-76.

[32] Bastuji-Garin S, Fouchard N, Bertocchi M, Roujeau JC, Revuz J, Wolkenstein P. SCORTEN: a severity-of-illness score for toxic epidermal necrolysis. J Invest Dermatol 2000;115(2):149-53.

[33] Guegan S, Bastuji-Garin S, Poszepczynska-Guigne E, Roujeau JC, Revuz J. Performance of the SCORTEN during the first five days of hospitalization to predict the prognosis of epidermal necrolysis. J Invest Dermatol 2006;126(2):272-6.

[34] Sekula P, Liss Y, Davidovici B, et al. Evaluation of SCORTEN on a cohort of patients with Stevens-Johnson syndrome and toxic epidermal necrolysis included in the RegiSCAR study. J Burn Care Res 2011;32(2):237-45.

[35] Yip LW, Thong BY, Lim J, et al. Ocular manifestations and complications of StevensJohnson syndrome and toxic epidermal necrolysis: an Asian series. Allergy 2007;62(5): 527-31.

[36] De Rojas MV, Dart JK, Saw VP. The natural history of Stevens Johnson syndrome: patterns of chronic ocular disease and the role of systemic immunosuppressive therapy. Br J Ophthalmol 2007;91(8):1048-53.

[37] Shammas MC, Lai EC, Sarkar JS, Yang J, Starr CE, Sippel KC. Management of acute Stevens-Johnson syndrome and toxic epidermal necrolysis utilizing amniotic membrane and topical corticosteroids. Am J Ophthalmol 2010;149(2):203-213 e2. 
[38] Magina S, Lisboa C, Leal V, Palmares J, Mesquita-Guimaraes J. Dermatological and ophthalmological sequels in toxic epidermal necrolysis. Dermatology 2003;207(1):33-6.

[39] Meneux E, Wolkenstein P, Haddad B, Roujeau JC, Revuz J, Paniel BJ. Vulvovaginal involvement in toxic epidermal necrolysis: a retrospective study of 40 cases. Obstet Gynecol 1998;91(2):283-7.

[40] Noel JC, Buxant F, Fayt I, Bebusschere G, Parent D. Vulval adenosis associated with toxic epidermal necrolysis. Br J Dermatol 2005;153(2):457-8.

[41] Revuz J, Penso D, Roujeau JC, et al. Toxic epidermal necrolysis. Clinical findings and prognosis factors in 87 patients. Arch Dermatol 1987;123(9):1160-5.

[42] Kamada N, Kinoshita K, Togawa Y, et al. Chronic pulmonary complications associated with toxic epidermal necrolysis: report of a severe case with anti-Ro/SS-A and a review of the published work. J Dermatol 2006;33(9):616-22.

[43] Shah AP, Xu H, Sime PJ, Trawick DR. Severe airflow obstruction and eosinophilic lung disease after Stevens-Johnson syndrome. Eur Respir J 2006;28(6):1276-9.

[44] Clayton NA, Kennedy PJ. Management of dysphagia in toxic epidermal necrolysis (TEN) and Stevens-Johnson syndrome (SJS). Dysphagia 2007;22(3):187-92.

[45] Pichler WJ, Adam J, Daubner B, Gentinetta T, Keller M, Yerly D. Drug hypersensitivity reactions: pathomechanism and clinical symptoms. Med Clin North Am 2010;94(4): 645-64, xv.

[46] Pichler WJ. Direct T-cell stimulations by drugs--bypassing the innate immune system. Toxicology 2005;209(2):95-100.

[47] Sanderson JP, Naisbitt DJ, Farrell J, et al. Sulfamethoxazole and its metabolite nitroso sulfamethoxazole stimulate dendritic cell costimulatory signaling. J Immunol 2007;178(9):5533-42.

[48] Chung WH, Hung SI, Yang JY, et al. Granulysin is a key mediator for disseminated keratinocyte death in Stevens-Johnson syndrome and toxic epidermal necrolysis. Nat Med 2008;14(12):1343-50.

[49] Gamen S, Hanson DA, Kaspar A, Naval J, Krensky AM, Anel A. Granulysin-induced apoptosis. I. Involvement of at least two distinct pathways. J Immunol 1998;161(4): 1758-64.

[50] Deng A, Chen S, Li Q, Lyu SC, Clayberger C, Krensky AM. Granulysin, a cytolytic molecule, is also a chemoattractant and proinflammatory activator. I Immunol 2005;174(9):5243-8.

[51] Viard I, Wehrli P, Bullani R, et al. Inhibition of toxic epidermal necrolysis by blockade of CD95 with human intravenous immunoglobulin. Science 1998;282(5388):490-3. 
[52] Viard-Leveugle I, Bullani RR, Meda P, et al. Intracellular localization of keratinocyte Fas ligand explains lack of cytolytic activity under physiological conditions. J Biol Chem 2003;278(18):16183-8.

[53] Abe R, Shimizu T, Shibaki A, Nakamura H, Watanabe H, Shimizu H. Toxic epidermal necrolysis and Stevens-Johnson syndrome are induced by soluble Fas ligand. Am J Pathol 2003;162(5):1515-20.

[54] Nassif A, Bensussan A, Dorothee G, et al. Drug specific cytotoxic T-cells in the skin lesions of a patient with toxic epidermal necrolysis. J Invest Dermatol 2002;118(4): 728-33.

[55] Takahashi R, Kano Y, Yamazaki Y, Kimishima M, Mizukawa Y, Shiohara T. Defective regulatory $\mathrm{T}$ cells in patients with severe drug eruptions: timing of the dysfunction is associated with the pathological phenotype and outcome. J Immunol 2009;182(12): 8071-9.

[56] Posadas SJ, Padial A, Torres MJ, et al. Delayed reactions to drugs show levels of perforin, granzyme B, and Fas-L to be related to disease severity. J Allergy Clin Immunol 2002;109(1):155-61.

[57] Nassif A, Bensussan A, Boumsell L, et al. Toxic epidermal necrolysis: effector cells are drug-specific cytotoxic T cells. J Allergy Clin Immunol 2004;114(5):1209-15.

[58] Hung SI, Chung WH, Chen YT. HLA-B genotyping to detect carbamazepine induced Stevens-Johnson syndrome: implications for personalizing medicine. Personalized Med. 2005;2:225-237.

[59] Hung SI, Chung WH, Chen YT. Genetics of severe drug hypersensitivity reactions in Han Chinese. In: Pichler WJ, ed. Drug Hypersensitivity. Basel.: Karger., 2007: 105-114.

[60] Chung WH, Hung SI, Hong HS, et al. Medical genetics: a marker for Stevens-Johnson syndrome. Nature 2004;428(6982):486.

[61] Hung SI, Chung WH, Jee SH, et al. Genetic susceptibility to carbamazepine-induced cutaneous adverse drug reactions. Pharmacogenet Genomics 2006;16(4):297-306.

[62] Lonjou C, Thomas L, Borot N, et al. A marker for Stevens-Johnson syndrome ...: ethnicity matters. Pharmacogenomics J 2006;6(4):265-8.

[63] Kaniwa N, Saito Y, Aihara M, et al. HLA-B locus in Japanese patients with anti-epileptics and allopurinol-related Stevens-Johnson syndrome and toxic epidermal necrolysis. Pharmacogenomics 2008;9(11):1617-22.

[64] McCormack M, Alfirevic A, Bourgeois S, et al. HLA-A*3101 and carbamazepine-induced hypersensitivity reactions in Europeans. N Engl J Med 2011;364(12):1134-43. 
[65] Ozeki T, Mushiroda T, Yowang A, et al. Genome-wide association study identifies HLA-A*3101 allele as a genetic risk factor for carbamazepine-induced cutaneous adverse drug reactions in Japanese population. Hum Mol Genet 2011;20(5):1034-41.

[66] Wen SH, Lai MJ, Yang KL. Human leukocyte antigen-A, -B, and -DRB1 haplotypes of cord blood units in the Tzu Chi Taiwan Cord Blood Bank. Hum Immunol 2008;69(7): 430-6.

[67] Hung SI, Chung WH, Liou LB, et al. HLA-B*5801 allele as a genetic marker for severe cutaneous adverse reactions caused by allopurinol. Proc Natl Acad Sci U S A 2005;102(11):4134-9.

[68] Lonjou C, Borot N, Sekula P, et al. A European study of HLA-B in Stevens-Johnson syndrome and toxic epidermal necrolysis related to five high-risk drugs. Pharmacogenet Genomics 2008;18(2):99-107.

[69] Daar AS, Singer PA. Pharmacogenetics and geographical ancestry: implications for drug development and global health. Nat Rev Genet 2005;6(3):241-6.

[70] Schmidt AH, Baier D, Solloch UV, et al. Estimation of high-resolution HLA-A, -B, -C, -DRB1 allele and haplotype frequencies based on 8862 German stem cell donors and implications for strategic donor registry planning. Hum Immunol 2009;70(11):895-902.

[71] Ueta M, Sotozono C, Inatomi T, Kojima K, Hamuro J, Kinoshita S. Association of Fas Ligand gene polymorphism with Stevens-Johnson syndrome. Br J Ophthalmol 2008;92(7):989-91.

[72] Ueta M, Sotozono C, Inatomi T, et al. Toll-like receptor 3 gene polymorphisms in Japanese patients with Stevens-Johnson syndrome. Br J Ophthalmol 2007;91(7):962-5.

[73] Ueta M, Sotozono C, Inatomi T, Kojima K, Hamuro J, Kinoshita S. Association of combined IL-13/IL-4R signaling pathway gene polymorphism with Stevens-Johnson syndrome accompanied by ocular surface complications. Invest Ophthalmol Vis Sci 2008;49(5):1809-13.

[74] http://formularyproductions.com/blackbox/carbamazepine.

[75] Chen P, Lin JJ, Lu CS, et al. Carbamazepine-induced toxic effects and HLA-B*1502 screening in Taiwan. N Engl J Med 2011;364(12):1126-33.

[76] Fernando SL, Broadfoot AJ. Prevention of severe cutaneous adverse drug reactions: the emerging value of pharmacogenetic screening. Cmaj 2010;182(5):476-80.

[77] Rauch A, Nolan D, Martin A, McKinnon E, Almeida C, Mallal S. Prospective genetic screening decreases the incidence of abacavir hypersensitivity reactions in the Western Australian HIV cohort study. Clin Infect Dis 2006;43(1):99-102.

[78] Halevy S, Ghislain PD, Mockenhaupt M, et al. Allopurinol is the most common cause of Stevens-Johnson syndrome and toxic epidermal necrolysis in Europe and Israel. $J$ Am Acad Dermatol 2008;58(1):25-32. 
[79] Stamp L, Gow P, Sharples K, Raill B. The optimal use of allopurinol: an audit of allopurinol use in South Auckland. Aust N Z J Med 2000;30(5):567-72.

[80] McInnes GT, Lawson DH, Jick H. Acute adverse reactions attributed to allopurinol in hospitalised patients. Ann Rheum Dis 1981;40(3):245-9.

[81] Hande KR, Noone RM, Stone WJ. Severe allopurinol toxicity. Description and guidelines for prevention in patients with renal insufficiency. Am J Med 1984;76(1):47-56.

[82] Kumar A, Edward N, White MI, Johnston PW, Catto GR. Allopurinol, erythema multiforme, and renal insufficiency. Bmj 1996;312(7024):173-4.

[83] Vazquez-Mellado J, Morales EM, Pacheco-Tena C, Burgos-Vargas R. Relation between adverse events associated with allopurinol and renal function in patients with gout. Ann Rheum Dis 2001;60(10):981-3.

[84] Dincer HE, Dincer AP, Levinson DJ. Asymptomatic hyperuricemia: to treat or not to treat. Cleve Clin J Med 2002;69(8):594, 597, 600-2 passim.

[85] Singer JZ, Wallace SL. The allopurinol hypersensitivity syndrome. Unnecessary morbidity and mortality. Arthritis Rheum 1986;29(1):82-7.

[86] Bellamy N, Brooks PM, Emmerson BT, Gilbert JR, Campbell J, McCredie M. A survey of current prescribing practices of anti-inflammatory and urate-lowering drugs in gouty arthritis in New South Wales and Queensland. Med J Aust 1989;151(9):531-2 535-7.

[87] Khoo BP, Leow YH. A review of inpatients with adverse drug reactions to allopurinol. Singapore Med J 2000;41(4):156-60.

[88] Schlienger RG, Shapiro LE, Shear NH. Lamotrigine-induced severe cutaneous adverse reactions. Epilepsia 1998;39 Suppl 7:S22-6.

[89] Mockenhaupt M, Messenheimer J, Tennis P, Schlingmann J. Risk of Stevens-Johnson syndrome and toxic epidermal necrolysis in new users of antiepileptics. Neurology 2005;64(7):1134-8.

[90] Yalcin B, Karaduman A. Stevens-Johnson syndrome associated with concomitant use of lamotrigine and valproic acid. J Am Acad Dermatol 2000;43(5 Pt 2):898-9.

[91] Wolkenstein P, Carriere V, Charue D, et al. A slow acetylator genotype is a risk factor for sulphonamide-induced toxic epidermal necrolysis and Stevens-Johnson syndrome. Pharmacogenetics 1995;5(4):255-8.

[92] Dietrich A, Kawakubo Y, Rzany B, Mockenhaupt M, Simon JC, Schopf E. Low N-acetylating capacity in patients with Stevens-Johnson syndrome and toxic epidermal necrolysis. Exp Dermatol 1995;4(5):313-6.

[93] Becker DS. Toxic epidermal necrolysis. Lancet 1998;351(9113):1417-20. 
[94] Quinn AM, Brown K, Bonish BK, et al. Uncovering histologic criteria with prognostic significance in toxic epidermal necrolysis. Arch Dermatol 2005;141(6):683-7.

[95] Abe R, Yoshioka N, Murata J, Fujita Y, Shimizu H. Granulysin as a marker for early diagnosis of the Stevens-Johnson syndrome. Ann Intern Med 2009;151(7):514-5.

[96] Wolkenstein P, Chosidow O, Flechet ML, et al. Patch testing in severe cutaneous adverse drug reactions, including Stevens-Johnson syndrome and toxic epidermal necrolysis. Contact Dermatitis 1996;35(4):234-6.

[97] Kano Y, Hirahara K, Mitsuyama Y, Takahashi R, Shiohara T. Utility of the lymphocyte transformation test in the diagnosis of drug sensitivity: dependence on its timing and the type of drug eruption. Allergy 2007;62(12):1439-44.

[98] Zawodniak A, Lochmatter P, Yerly D, et al. In vitro detection of cytotoxic T and NK cells in peripheral blood of patients with various drug-induced skin diseases. Allergy 2010;65(3):376-84.

[99] Bronnimann M, Yawalkar N. Histopathology of drug-induced exanthems: is there a role in diagnosis of drug allergy? Curr Opin Allergy Clin Immunol 2005;5(4):317-21.

[100] Mockenhaupt M. Severe drug-induced skin reactions: clinical pattern, diagnostics and therapy. J Dtsch Dermatol Ges 2009;7(2):142-60; quiz 161-2.

[101] Mockenhaupt M, Idzko M, Grosber M, Schopf E, Norgauer J. Epidemiology of staphylococcal scalded skin syndrome in Germany. J Invest Dermatol 2005;124(4):700-3.

[102] Yamasaki O, Yamaguchi T, Sugai M, et al. Clinical manifestations of staphylococcal scalded-skin syndrome depend on serotypes of exfoliative toxins. J Clin Microbiol 2005;43(4):1890-3.

[103] Ladhani S. Recent developments in staphylococcal scalded skin syndrome. Clin Microbiol Infect 2001;7(6):301-7.

[104] Lappin E, Ferguson AJ. Gram-positive toxic shock syndromes. Lancet Infect Dis 2009;9(5):281-90.

[105] Tonev S, Vasileva S, Kadurina M. Depot sulfonamid associated linear IgA bullous dermatosis with erythema multiforme-like clinical features. J Eur Acad Dermatol Venereol 1998;11(2):165-8.

[106] Anhalt GJ, Kim SC, Stanley JR, et al. Paraneoplastic pemphigus. An autoimmune mucocutaneous disease associated with neoplasia. N Engl J Med 1990;323(25):1729-35.

[107] Wade MS, Black MM. Paraneoplastic pemphigus: a brief update. Australas J Dermatol 2005;46(1):1-8; quiz 9-10.

[108] Ayoub N. [Pemphigus and pemphigus-triggering drugs]. Ann Dermatol Venereol 2005;132(6-7 Pt 1):595. 
[109] Brenner S, Bialy-Golan A, Ruocco V. Drug-induced pemphigus. Clin Dermatol 1998;16(3):393-7.

[110] Mutasim DF, Pelc NJ, Anhalt GJ. Drug-induced pemphigus. Dermatol Clin 1993;11(3): 463-71.

[111] Bastuji-Garin S, Joly P, Picard-Dahan C, et al. Drugs associated with bullous pemphigoid. A case-control study. Arch Dermatol 1996;132(3):272-6.

[112] Fellner MJ. Drug-induced bullous pemphigoid. Clin Dermatol 1993;11(4):515-20.

[113] Olasz EB, Yancey KB. Bullous pemphigoid and related subepidermal autoimmune blistering diseases. Curr Dir Autoimmun 2008;10:141-66.

[114] Correia O, Delgado L, Barbosa IL, Campilho F, Fleming-Torrinha J. Increased interleukin 10, tumor necrosis factor alpha, and interleukin 6 levels in blister fluid of toxic epidermal necrolysis. J Am Acad Dermatol 2002;47(1):58-62.

[115] Schulz JT, 3rd, Sheridan RL. Severe desquamating disorder after liver transplant: toxic epidermal necrolysis or graft versus host disease? J Burns Wounds 2006;5:e1.

[116] Vargas-Diez E, Garcia-Diez A, Marin A, Fernandez-Herrera J. Life-threatening graftvs-host disease. Clin Dermatol 2005;23(3):285-300.

[117] Friedman KJ, LeBoit PE, Farmer ER. Acute follicular graft-vs-host reaction. A distinct clinicopathologic presentation. Arch Dermatol 1988;124(5):688-91.

[118] Lin JH, Sheu HM, Lee JY. Acute generalized exanthematous pustulosis with erythema multiforme-like lesions. Eur J Dermatol 2002;12(5):475-8.

[119] Garcia-Doval I, LeCleach L, Bocquet H, Otero XL, Roujeau JC. Toxic epidermal necrolysis and Stevens-Johnson syndrome: does early withdrawal of causative drugs decrease the risk of death? Arch Dermatol 2000;136(3):323-7.

[120] Palmieri TL, Greenhalgh DG, Saffle JR, et al. A multicenter review of toxic epidermal necrolysis treated in U.S. burn centers at the end of the twentieth century. J Burn Care Rehabil 2002;23(2):87-96.

[121] Schulz JT, Sheridan RL, Ryan CM, MacKool B, Tompkins RG. A 10-year experience with toxic epidermal necrolysis. J Burn Care Rehabil 2000;21(3):199-204.

[122] Shiga S, Cartotto R. What are the fluid requirements in toxic epidermal necrolysis? J Burn Care Res 2010;31(1):100-4.

[123] Mayes T, Gottschlich M, Khoury J, Warner P, Kagan R. Energy requirements of pediatric patients with Stevens-Johnson syndrome and toxic epidermal necrolysis. Nutr Clin Pract 2008;23(5):547-50.

[124] Gravante G, Esposito G, Piazzolla M, Marianetti M, Delogu D, Montone A. Nutrition of toxic epidermal necrolysis. J Hum Nutr Diet 2006;19(2):152-3; author reply 153-5. 
[125] Spies M, Sanford AP, Aili Low JF, Wolf SE, Herndon DN. Treatment of extensive toxic epidermal necrolysis in children. Pediatrics 2001;108(5):1162-8.

[126] Dorafshar AH, Dickie SR, Cohn AB, et al. Antishear therapy for toxic epidermal necrolysis: an alternative treatment approach. Plast Reconstr Surg 2008;122(1):154-60.

[127] Dalli RL, Kumar R, Kennedy P, Maitz P, Lee S, Johnson R. Toxic epidermal necrolysis/Stevens-Johnson syndrome: current trends in management. ANZ J Surg 2007;77(8):671-6.

[128] Huang SH, Yang PS, Wu SH, et al. Aquacel Ag with Vaseline gauze in the management of toxic epidermal necrolysis (TEN). Burns 2009;36(1):121-6.

[129] Boorboor P, Vogt PM, Bechara FG, et al. Toxic epidermal necrolysis: use of Biobrane or skin coverage reduces pain, improves mobilisation and decreases infection in elderly patients. Burns 2008;34(4):487-92.

[130] Pruitt BA, Jr. Burn treatment for the unburned. Jama 1987;257(16):2207-8.

[131] Gomes JA, Romano A, Santos MS, Dua HS. Amniotic membrane use in ophthalmology. Curr Opin Ophthalmol 2005;16(4):233-40.

[132] Rasmussen JE. Erythema multiforme in children. Response to treatment with systemic corticosteroids. Br J Dermatol 1976;95(2):181-6.

[133] Engelhardt SL, Schurr MJ, Helgerson RB. Toxic epidermal necrolysis: an analysis of referral patterns and steroid usage. J Burn Care Rehabil 1997;18(6):520-4.

[134] Ginsburg CM. Stevens-Johnson syndrome in children. Pediatr Infect Dis 1982;1(3): 155-8.

[135] Halebian PH, Corder VJ, Madden MR, Finklestein JL, Shires GT. Improved burn center survival of patients with toxic epidermal necrolysis managed without corticosteroids. Ann Surg 1986;204(5):503-12.

[136] Guibal F, Bastuji-Garin S, Chosidow O, Saiag P, Revuz J, Roujeau JC. Characteristics of toxic epidermal necrolysis in patients undergoing long-term glucocorticoid therapy. Arch Dermatol 1995;131(6):669-72.

[137] Samimi SS, Siegfried E. Stevens-Johnson syndrome developing in a girl with systemic lupus erythematosus on high-dose corticosteroid therapy. Pediatr Dermatol 2002;19(1):52-5.

[138] Kakourou T, Klontza D, Soteropoulou F, Kattamis C. Corticosteroid treatment of erythema multiforme major (Stevens-Johnson syndrome) in children. Eur J Pediatr 1997;156(2):90-3.

[139] Criton S, Devi K, Sridevi PK, Asokan PU. Toxic epidermal necrolysis--a retrospective study. Int J Dermatol 1997;36(12):923-5. 
[140] Kardaun SH, Jonkman MF. Dexamethasone pulse therapy for Stevens-Johnson syndrome/toxic epidermal necrolysis. Acta Derm Venereol 2007;87(2):144-8.

[141] Yamane Y, Aihara M, Tatewaki S, et al. [Analysis of treatments and deceased cases of severe adverse drug reactions--analysis of 46 cases of Stevens-Johnson syndrome and toxic epidermal necrolysis]. Arerugi 2009;58(5):537-47.

[142] Araki Y, Sotozono C, Inatomi T, et al. Successful treatment of Stevens-Johnson syndrome with steroid pulse therapy at disease onset. Am J Ophthalmol 2009;147(6): 1004-11, 1011 e1.

[143] Prins C, Vittorio C, Padilla RS, et al. Effect of high-dose intravenous immunoglobulin therapy in Stevens-Johnson syndrome: a retrospective, multicenter study. Dermatology 2003;207(1):96-9.

[144] Campione E, Marulli GC, Carrozzo AM, Chimenti MS, Costanzo A, Bianchi L. Highdose intravenous immunoglobulin for severe drug reactions: efficacy in toxic epidermal necrolysis. Acta Derm Venereol 2003;83(6):430-2.

[145] Metry DW, Jung P, Levy ML. Use of intravenous immunoglobulin in children with stevens-johnson syndrome and toxic epidermal necrolysis: seven cases and review of the literature. Pediatrics 2003;112(6 Pt 1):1430-6.

[146] Yang Y, Xu J, Li F, Zhu X. Combination therapy of intravenous immunoglobulin and corticosteroid in the treatment of toxic epidermal necrolysis and Stevens-Johnson syndrome: a retrospective comparative study in China. Int J Dermatol 2009;48(10): $1122-8$.

[147] Bachot N, Revuz J, Roujeau JC. Intravenous immunoglobulin treatment for StevensJohnson syndrome and toxic epidermal necrolysis: a prospective noncomparative study showing no benefit on mortality or progression. Arch Dermatol 2003;139(1): 33-6.

[148] Brown KM, Silver GM, Halerz M, Walaszek P, Sandroni A, Gamelli RL. Toxic epidermal necrolysis: does immunoglobulin make a difference? J Burn Care Rehabil 2004;25(1):81-8.

[149] Shortt R, Gomez M, Mittman N, Cartotto R. Intravenous immunoglobulin does not improve outcome in toxic epidermal necrolysis. J Burn Care Rehabil 2004;25(3):246-55.

[150] Pasic S. Intravenous immunoglobulin in toxic epidermal necrolysis. Int J Dermatol 2006;45(9):1117-8.

[151] Schneck J, Fagot JP, Sekula P, Sassolas B, Roujeau JC, Mockenhaupt M. Effects of treatments on the mortality of Stevens-Johnson syndrome and toxic epidermal necrolysis: A retrospective study on patients included in the prospective EuroSCAR Study. J Am Acad Dermatol 2008;58(1):33-40. 
[152] Renfro L, Grant-Kels JM, Daman LA. Drug-induced toxic epidermal necrolysis treated with cyclosporin. Int J Dermatol 1989;28(7):441-4.

[153] Zaki I, Patel S, Reed R, Dalziel KL. Toxic epidermal necrolysis associated with severe hypocalcaemia, and treated with cyclosporin. Br J Dermatol 1995;133(2):337-8.

[154] Sullivan JR, Watson A. Lamotrigine-induced toxic epidermal necrolysis treated with intravenous cyclosporin: a discussion of pathogenesis and immunosuppressive management. Australas J Dermatol 1996;37(4):208-12.

[155] Hewitt J, Ormerod AD. Toxic epidermal necrolysis treated with cyclosporin. Clin Exp Dermatol 1992;17(4):264-5.

[156] Jarrett P, Ha T, Snow J. Toxic epidermal necrolysis and cyclosporin. Clin Exp Dermatol 1997;22(5):254.

[157] Arevalo JM, Lorente JA, Gonzalez-Herrada C, Jimenez-Reyes J. Treatment of toxic epidermal necrolysis with cyclosporin A. J Trauma 2000;48(3):473-8.

[158] Robak E, Robak T, Gora-Tybor J, et al. Toxic epidermal necrolysis in a patient with severe aplastic anemia treated with cyclosporin A and G-CSF. J Med 2001;32(1-2): $31-9$.

[159] Yung A, Agnew K, Snow J, Oliver F. Two unusual cases of toxic epidermal necrolysis. Australas J Dermatol 2002;43(1):35-8.

[160] Hashim N, Bandara D, Tan E, Ilchyshyn A. Early cyclosporine treatment of incipient toxic epidermal necrolysis induced by concomitant use of lamotrigine and sodium valproate. Acta Derm Venereol 2004;84(1):90-1.

[161] Valeyrie-Allanore L, Wolkenstein P, Brochard L, et al. Open trial of ciclosporin treatment for Stevens-Johnson syndrome and toxic epidermal necrolysis. Br J Dermatol 2010;163(4):847-53.

[162] Sakellariou G, Koukoudis P, Karpouzas J, et al. Plasma exchange (PE) treatment in drug-induced toxic epidermal necrolysis (TEN). Int J Artif Organs 1991;14(10):634-8.

[163] Chaidemenos GC, Chrysomallis F, Sombolos K, Mourellou O, Ioannides D, Papakonstantinou M. Plasmapheresis in toxic epidermal necrolysis. Int J Dermatol 1997;36(3): 218-21.

[164] Egan CA, Grant WJ, Morris SE, Saffle JR, Zone JJ. Plasmapheresis as an adjunct treatment in toxic epidermal necrolysis. J Am Acad Dermatol 1999;40(3):458-61.

[165] Bamichas G, Natse T, Christidou F, et al. Plasma exchange in patients with toxic epidermal necrolysis. Ther Apher 2002;6(3):225-8.

[166] Furubacke A, Berlin G, Anderson C, Sjoberg F. Lack of significant treatment effect of plasma exchange in the treatment of drug-induced toxic epidermal necrolysis? Intensive Care Med 1999;25(11):1307-10. 
[167] Paquet P, Paquet F, Al Saleh W, Reper P, Vanderkelen A, Pierard GE. Immunoregulatory effector cells in drug-induced toxic epidermal necrolysis. Am J Dermatopathol 2000;22(5):413-7.

[168] Fischer M, Fiedler E, Marsch WC, Wohlrab J. Antitumour necrosis factor-alpha antibodies (infliximab) in the treatment of a patient with toxic epidermal necrolysis. $\mathrm{Br} \mathrm{J}$ Dermatol 2002;146(4):707-9.

[169] Hunger RE, Hunziker T, Buettiker U, Braathen LR, Yawalkar N. Rapid resolution of toxic epidermal necrolysis with anti-TNF-alpha treatment. J Allergy Clin Immunol 2005;116(4):923-4.

[170] Meiss F, Helmbold P, Meykadeh N, Gaber G, Marsch W, Fischer M. Overlap of acute generalized exanthematous pustulosis and toxic epidermal necrolysis: response to antitumour necrosis factor-alpha antibody infliximab: report of three cases. J Eur Acad Dermatol Venereol 2007;21(5):717-9.

[171] Wojtkiewicz A, Wysocki M, Fortuna J, Chrupek M, Matczuk M, Koltan A. Beneficial and rapid effect of infliximab on the course of toxic epidermal necrolysis. Acta Derm Venereol 2008;88(4):420-1.

[172] Gubinelli E, Canzona F, Tonanzi T, Raskovic D, Didona B. Toxic epidermal necrolysis successfully treated with etanercept. J Dermatol 2009;36(3):150-3.

[173] Sadighha A. Etanercept in the treatment of a patient with acute generalized exanthematous pustulosis/toxic epidermal necrolysis: definition of a new model based on translational research. Int J Dermatol 2009;48(8):913-4.

[174] Velez A, Moreno JC. Toxic epidermal necrolysis treated with N-acetylcysteine. J Am Acad Dermatol 2002;46(3):469-70.

[175] Claes P, Wintzen M, Allard S, Simons P, De Coninck A, Lacor P. Nevirapine-induced toxic epidermal necrolysis and toxic hepatitis treated successfully with a combination of intravenous immunoglobulins and N-acetylcysteine. Eur J Intern Med 2004;15(4): 255-258.

[176] Paquet P, Jacob E, Damas P, Pierard GE. Recurrent fatal drug-induced toxic epidermal necrolysis (Lyell's syndrome) after putative beta-lactam cross-reactivity: Case report and scrutiny of antibiotic imputability. Crit Care Med 2002;30(11):2580-3.

[177] Lam A, Randhawa I, Klaustermeyer W. Cephalosporin induced toxic epidermal necrolysis and subsequent penicillin drug exanthem. Allergol Int 2008;57(3):281-4.

[178] Merritt HH, Putnam TJ. Sodium diphenylhydantoinate in the treatment of convulsive disorders. JAMA 1938;111:1068-1073.

[179] Chaiken BH, Goldberg BI, Segal JP. Dilantin sensitivity; report of a case of hepatitis with jaundice, pyrexia and exfoliative dermatitis. N Engl J Med 1950;242(23):897-8. 
[180] Saltzstein SL, Ackerman LV. Lymphadenopathy induced by anticonvulsant drugs and mimicking clinically pathologically malignant lymphomas. Cancer 1959;12(1): $164-82$.

[181] Shear NH, Spielberg SP. Anticonvulsant hypersensitivity syndrome. In vitro assessment of risk. J Clin Invest 1988;82(6):1826-32.

[182] Bocquet H, Bagot M, Roujeau JC. Drug-induced pseudolymphoma and drug hypersensitivity syndrome (Drug Rash with Eosinophilia and Systemic Symptoms: DRESS). Semin Cutan Med Surg 1996;15(4):250-7.

[183] Suzuki Y, Inagi R, Aono T, Yamanishi K, Shiohara T. Human herpesvirus 6 infection as a risk factor for the development of severe drug-induced hypersensitivity syndrome. Arch Dermatol 1998;134(9):1108-12.

[184] Shiohara T, Inaoka M, Kano Y. Drug-induced hypersensitivity syndrome (DIHS): a reaction induced by a complex interplay among herpesviruses and antiviral and antidrug immune responses. Allergol Int 2006;55(1):1-8.

[185] Gennis MA, Vemuri R, Burns EA, Hill JV, Miller MA, Spielberg SP. Familial occurrence of hypersensitivity to phenytoin. Am J Med 1991;91(6):631-4.

[186] Mockenhaupt M. Epidemiology and causes of severe cutaneous adverse drug reactions. In: Pichler WJ, ed. Drug hypersensitivity. Basel: Karger, 2007: 18-31.

[187] Kardaun SH, Sidoroff A, Valeyrie-Allanore L, et al. Variability in the clinical pattern of cutaneous side-effects of drugs with systemic symptoms: does a DRESS syndrome really exist? Br J Dermatol 2007;156(3):609-11.

[188] Shiohara T, Iijima M, Ikezawa Z, Hashimoto K. The diagnosis of a DRESS syndrome has been sufficiently established on the basis of typical clinical features and viral reactivations. Br J Dermatol 2007;156(5):1083-4.

[189] Kano Y, Inaoka M, Shiohara T. Association between anticonvulsant hypersensitivity syndrome and human herpesvirus 6 reactivation and hypogammaglobulinemia. Arch Dermatol 2004;140(2):183-8.

[190] Shiohara T, Takahashi R, Kano Y. Drug-induced hypersensitivity syndrome (DIHS): a reaction induced by a complex interplay among herpesviruses and antiviral and antidrug immune responses. In: Pichler WJ, ed. Allergol Int. Basel: Karger, 2007: 251-266.

[191] Roujeau JC, Stern RS. Severe adverse cutaneous reactions to drugs. N Engl J Med 1994;331(19):1272-85.

[192] Kano Y, Shiohara T. The variable clinical picture of drug-induced hypersensitivity syndrome/drug rash with eosinophilia and systemic symptoms in relation to the eliciting drug. Immunol Allergy Clin North Am 2009;29(3):481-501. 
[193] Mallal S, Nolan D, Witt C, et al. Association between presence of HLA-B*5701, HLADR7, and HLA-DQ3 and hypersensitivity to HIV-1 reverse-transcriptase inhibitor abacavir. Lancet 2002;359(9308):727-32.

[194] Ben m'rad M, Leclerc-Mercier S, Blanche P, et al. Drug-induced hypersensitivity syndrome: clinical and biologic disease patterns in 24 patients. Medicine (Baltimore) 2009;88(3):131-40.

[195] Masaki T, Fukunaga A, Tohyama M, et al. Human herpes virus 6 encephalitis in allopurinol-induced hypersensitivity syndrome. Acta Derm Venereol 2003;83(2):128-31.

[196] Sakuma K, Kano Y, Fukuhara M, Shiohara T. Syndrome of inappropriate secretion of antidiuretic hormone associated with limbic encephalitis in a patient with drug-induced hypersensitivity syndrome. Clin Exp Dermatol 2008;33(3):287-90.

[197] Asano Y, Kagawa H, Kano Y, Shiohara T. Cytomegalovirus disease during severe drug eruptions: report of 2 cases and retrospective study of 18 patients with druginduced hypersensitivity syndrome. Arch Dermatol 2009;145(9):1030-6.

[198] Descamps V, Bouscarat F, Laglenne S, et al. Human herpesvirus 6 infection associated with anticonvulsant hypersensitivity syndrome and reactive haemophagocytic syndrome. Br J Dermatol 1997;137(4):605-8.

[199] Lazoglu AH, Boglioli LR, Dorsett B, Macris NT. Phenytoin-related immunodeficiency associated with Loeffler's syndrome. Ann Allergy Asthma Immunol 1995;74(6): 479-82.

[200] Kano Y, Hiraharas K, Sakuma K, Shiohara T. Several herpesviruses can reactivate in a severe drug-induced multiorgan reaction in the same sequential order as in graftversus-host disease. Br J Dermatol 2006;155(2):301-6.

[201] Aota N, Shiohara T. Viral connection between drug rashes and autoimmune diseases: how autoimmune responses are generated after resolution of drug rashes. Autoimmun Rev 2009;8(6):488-94.

[202] Chiou CC, Chung WH, Hung SI, Yang LC, Hong HS. Fulminant type 1 diabetes mellitus caused by drug hypersensitivity syndrome with human herpesvirus 6 infection. J Am Acad Dermatol 2006;54(2 Suppl):S14-7.

[203] Ozaki N, Miura Y, Sakakibara A, Oiso Y. A case of hypersensitivity syndrome induced by methimazole for Graves' disease. Thyroid 2005;15(12):1333-6.

[204] Kano Y, Sakuma K, Shiohara T. Sclerodermoid graft-versus-host disease-like lesions occurring after drug-induced hypersensitivity syndrome. Br J Dermatol 2007;156(5): 1061-3.

[205] Aota N, Hirahara K, Kano Y, Fukuoka T, Yamada A, Shiohara T. Systemic lupus erythematosus presenting with Kikuchi-Fujimoto's disease as a long-term sequela of 
drug-induced hypersensitivity syndrome. A possible role of Epstein-Barr virus reactivation. Dermatology 2009;218(3):275-7.

[206] Kijima A, Inui S, Nakamura T, Itami S, Katayama I. Does drug-induced hypersensitivity syndrome elicit bullous pemphigoid? Allergol Int 2008;57(2):181-2.

[207] Hetherington S, McGuirk S, Powell G, et al. Hypersensitivity reactions during therapy with the nucleoside reverse transcriptase inhibitor abacavir. Clin Ther 2001;23(10): 1603-14.

[208] Peyriere H, Guillemin V, Lotthe A, et al. Reasons for early abacavir discontinuation in HIV-infected patients. Ann Pharmacother 2003;37(10):1392-7.

[209] Peyriere H, Dereure O, Breton H, et al. Variability in the clinical pattern of cutaneous side-effects of drugs with systemic symptoms: does a DRESS syndrome really exist? Br J Dermatol 2006;155(2):422-8.

[210] Fernando SL, Henderson CJ, O'Connor KS. Drug-induced hypersensitivity syndrome with superficial granulomatous dermatitis--a novel finding. Am J Dermatopathol 2009;31(6):611-3.

[211] Santiago F, Goncalo M, Vieira R, Coelho S, Figueiredo A. Epicutaneous patch testing in drug hypersensitivity syndrome (DRESS). Contact Dermatitis 2010;62(1):47-53.

[212] Phillips EJ, Wong GA, Kaul R, et al. Clinical and immunogenetic correlates of abacavir hypersensitivity. Aids 2005;19(9):979-81.

[213] Hirahara K, Kano Y, Mitsuyama Y, Takahashi R, Kimishima M, Shiohara T. Differences in immunological alterations and underlying viral infections in two well-defined severe drug eruptions. Clin Exp Dermatol 2010;35(8):863-8.

[214] Hughes AR, Mosteller M, Bansal AT, et al. Association of genetic variations in HLA$B$ region with hypersensitivity to abacavir in some, but not all, populations. Pharmacogenomics 2004;5(2):203-11.

[215] Park WB, Choe PG, Song KH, et al. Should HLA-B*5701 screening be performed in every ethnic group before starting abacavir? Clin Infect Dis 2009;48(3):365-7.

[216] Cao K, Hollenbach J, Shi X, Shi W, Chopek M, Fernandez-Vina MA. Analysis of the frequencies of HLA-A, B, and C alleles and haplotypes in the five major ethnic groups of the United States reveals high levels of diversity in these loci and contrasting distribution patterns in these populations. Hum Immunol 2001;62(9):1009-30.

[217] Mallal S, Phillips E, Carosi G, et al. HLA-B*5701 screening for hypersensitivity to abacavir. N Engl J Med 2008;358(6):568-79.

[218] Fields KS, Petersen MJ, Chiao E, Tristani-Firouzi P. Case reports: treatment of nevirapine-associated dress syndrome with intravenous immune globulin (IVIG). J Drugs Dermatol 2005;4(4):510-3. 
[219] Santos RP, Ramilo O, Barton T. Nevirapine-associated rash with eosinophilia and systemic symptoms in a child with human immunodeficiency virus infection. Pediatr Infect Dis J 2007;26(11):1053-6.

[220] Higuchi M, Agatsuma T, Iizima M, et al. A case of drug-induced hypersensitivity syndrome with multiple organ involvement treated with plasma exchange. Ther Apher Dial 2005;9(5):412-6.

[221] Shaughnessy KK, Bouchard SM, Mohr MR, Herre JM, Salkey KS. Minocycline-induced drug reaction with eosinophilia and systemic symptoms (DRESS) syndrome with persistent myocarditis. J Am Acad Dermatol 2010;62(2):315-8.

[222] Beylot C, Bioulac P, Doutre MS. [Acute generalized exanthematic pustuloses (four cases) (author's transl)]. Ann Dermatol Venereol 1980;107(1-2):37-48.

[223] Sidoroff A, Halevy S, Bavinck JN, Vaillant L, Roujeau JC. Acute generalized exanthematous pustulosis (AGEP)--a clinical reaction pattern. J Cutan Pathol 2001;28(3): 113-9.

[224] Chang SL, Huang YH, Yang CH, Hu S, Hong HS. Clinical manifestations and characteristics of patients with acute generalized exanthematous pustulosis in Asia. Acta Derm Venereol 2008;88(4):363-5.

[225] Davidovici B, Dodiuk-Gad R, Rozenman D, Halevy S. Profile of acute generalized exanthematous pustulosis in Israel during 2002-2005: results of the RegiSCAR Study. Isr Med Assoc J 2008;10(6):410-2.

[226] Zhang JL, Chen X, Li J, Xie HF. [Clinical analysis of childhood acute generalized exanthematous pustulosis]. Zhongguo Dang Dai Er Ke Za Zhi 2008;10(4):497-9.

[227] Roujeau JC. Clinical heterogeneity of drug hypersensitivity. Toxicology 2005;209(2): 123-9.

[228] Brandenburg VM, Kurts C, Eitner F, Hamilton-Williams E, Heintz B. Acute reversible renal failure in acute generalized exanthematous pustulosis. Nephrol Dial Transplant 2002;17(10):1857-8.

[229] Belhadjali H, Mandhouj S, Moussa A, et al. Mercury-induced acute generalized exanthematous pustulosis misdiagnosed as a drug-related case. Contact Dermatitis 2008;59(1):52-4.

[230] Belhadjali H, Ghannouchi N, Njim L, et al. Acute generalized exanthematous pustulosis induced by bufexamac in an atopic girl. Contact Dermatitis 2008;58(4):247-8.

[231] Rouchouse B, Bonnefoy M, Pallot B, Jacquelin L, Dimoux-Dime G, Claudy AL. Acute generalized exanthematous pustular dermatitis and viral infection. Dermatologica 1986;173(4):180-4.

[232] Feio AB, Apetato M, Costa MM, Sa J, Alcantara J. [Acute generalized exanthematous pustulosis due to Coxsackie B4 virus]. Acta Med Port 1997;10(6-7):487-91. 
[233] Haro-Gabaldon V, Sanchez-Sanchez-Vizcaino J, Ruiz-Avila P, Gutierrez-Fernandez J, Linares J, Naranjo-Sintes R. Acute generalized exanthematous pustulosis with cytomegalovirus infection. Int J Dermatol 1996;35(10):735-7.

[234] Naides SJ. Rheumatic manifestations of parvovirus B19 infection. Rheum Dis Clin North Am 1998;24(2):375-401.

[235] Manzano S, Guggisberg D, Hammann C, Laubscher B. [Acute generalized exanthematous pustulosis: first case associated with a Chlamydia pneumoniae infection]. Arch Pediatr 2006;13(9):1230-2.

[236] Klein N, Hartmann M, Helmbold P, Enk A. [Acute generalized exanthematous pustulosis associated with recurrent urinary tract infections]. Hautarzt 2009;60(3):226-8.

[237] Davidovici BB, Pavel D, Cagnano E, Rozenman D, Halevy S. Acute generalized exanthematous pustulosis following a spider bite: report of 3 cases. J Am Acad Dermatol 2006;55(3):525-9.

[238] Birnie AJ, Litlewood SM. Acute generalized exanthematous pustulosis does not always have a drug-related cause. Br J Dermatol 2008;159(2):492-3.

[239] Schmid S, Kuechler PC, Britschgi M, et al. Acute generalized exanthematous pustulosis: role of cytotoxic T cells in pustule formation. Am J Pathol 2002;161(6):2079-86.

[240] Schaerli P, Britschgi M, Keller M, et al. Characterization of human T cells that regulate neutrophilic skin inflammation. J Immunol 2004;173(3):2151-8.

[241] Lazarov A, Livni E, Halevy S. Generalized pustular drug eruptions: confirmation by in vitro tests. J Eur Acad Dermatol Venereol 1998;10(1):36-41.

[242] Halevy S, Cohen A, Livni E. Acute generalized exanthematous pustulosis associated with polysensitivity to paracetamol and bromhexine: the diagnostic role of in vitro interferon-gamma release test. Clin Exp Dermatol 2000;25(8):652-4.

[243] Girardi M, Duncan KO, Tigelaar RE, Imaeda S, Watsky KL, McNiff JM. Cross-comparison of patch test and lymphocyte proliferation responses in patients with a history of acute generalized exanthematous pustulosis. Am J Dermatopathol 2005;27(4): 343-6.

[244] Britschgi M, Steiner UC, Schmid S, et al. T-cell involvement in drug-induced acute generalized exanthematous pustulosis. J Clin Invest 2001;107(11):1433-41.

[245] Mashiah J, Brenner S. A systemic reaction to patch testing for the evaluation of acute generalized exanthematous pustulosis. Arch Dermatol 2003;139(9):1181-3.

[246] Thomas E, Bellon T, Barranco P, et al. Acute generalized exanthematous pustulosis due to tetrazepam. J Investig Allergol Clin Immunol 2008;18(2):119-22. 
[247] Halevy S, Cohen AD, Grossman N. Clinical implications of in vitro drug-induced interferon gamma release from peripheral blood lymphocytes in cutaneous adverse drug reactions. J Am Acad Dermatol 2005;52(2):254-61.

[248] Tamir E, Wohl Y, Mashiah J, Brenner S. Acute generalized exanthematous pustulosis: a retrospective analysis showing a clear predilection for women. Skinmed 2006;5(4): 186-8. 
